\title{
Welding of magnesium and its alloys: an overview of methods and process parameters and their effects on mechanical behaviour and structural integrity of the welds
}

\author{
Desmond Edem Primus Klenam ${ }^{1,2, *}$ (D), Gabriel Seun Ogunwande ${ }^{3}\left(\mathbb{D}\right.$, Taiwo Omotosho ${ }^{3}$ (D) Blessing Ozah ${ }^{3}$ (D) \\ Nthabiseng Beauty Maledi (D), Silas Ithete $\operatorname{Hango}^{5}$ (D), Adefunke Abosede Fabuyide ${ }^{2}$ (D), Lesego Mohlala ${ }^{4}$, \\ Josias Willem van der Merwe ${ }^{2}$ (D), and Michael Oluwatosin Bodunrin ${ }^{2}$ (D) \\ ${ }^{1}$ Academic Development Unit, Faculty of Engineering and the Built Environment, University of the Witwatersrand, WITS \\ 2050, Johannesburg, South Africa \\ 2 School of Chemical and Metallurgical Engineering, University of the Witwatersrand, WITS 2050, Johannesburg, South Africa \\ ${ }^{3}$ Department of Metallurgical and Materials Engineering, Federal University of Technology Akure, PMB 704, Ondo State, Nigeria \\ ${ }^{4}$ Department of Metallurgical Engineering, University of Johannesburg, South Africa \\ ${ }^{5}$ Department of Mechanical and Metallurgical Engineering, University of Namibia P. O. Box 3624, Ongwediva, Namibia.
}

Received: 30 July 2021 / Accepted: 29 October 2021

\begin{abstract}
An overview of welding methods and process parameters and its effects on mechanical behaviour and structural integrity of magnesium and its alloys are discussed. These alloys are less dense and beneficial structural alloys for improved energy efficiency, eco-friendliness and driver of circular economic model for sustainable design and innovative ecosystem. While the application of Mg-alloys is projected to increase, understanding the mechanical behaviour and structural integrity of welded joints are critical. Thus, fusion and solid-state welding processes of these alloys are discussed with emphasis on mechanical characterization. Laser welding is the most effective fusion welding technique for most $\mathrm{Mg}$ alloys whereas, the predominant solid-state method is friction stir welding. The importance of process variables such as heat inputs, welding velocity (speed) and post weld treatments on the microstructural evolution, on mechanical and physical properties of the distinct zones of the weld joints are described. The weldment is the most susceptible to failure due to phase transformation, defects such as microporosity and relatively coarse grain sizes after solidification. The implication of the design of quality weld joints of $\mathrm{Mg}$ alloys are explored with areas for future research directions briefly discussed.
\end{abstract}

Keywords: Welding metallurgy / magnesium and its alloys / mechanical and microstructural characterization / fusion welding / weld defects / post weld treatment

\section{Introduction}

Magnesium and related alloys are great engineering alloys from research and industrial point of view. These alloys have favourable high strength-to-weight ratio [1-4], splendid electromagnetic interference (EMI) shielding resistance, strong thermal conductivity, great damping capacity [5,6] and ease to recycle [7], which is critical to circular economic model. These properties have made the alloys attractive for some engineering applications in the automobiles, aeronautical, and biomedical industries. The utilization of $\mathrm{Mg}$ alloys as biomaterials are not only due to excellent biocompatibility, but also by its intrinsic properties, especially the rate of dissolution in body

\footnotetext{
* e-mail: desprimus@gmail.com
}

fluids [8]. The density and yield strengths of these alloys are similar to that of human bone [9]. The closeness of elastic moduli and densities of these alloys to the human bone solves the implant-bone mismatch [9].

Magnesium is a naturally occurring element in bones and required for metabolism in human beings. It contributes to bone growth and stabilization and any deficit in the humans can lead to osteoporosis and other bone related diseases [9]. The use of Mg-based alloys as implants are beneficial as they dissolve easily into the blood stream during the healing process without causing any adverse effect when controlled $[9,10]$. Magnesium is a green engineering material [11]. These materials and their waste product do not emit toxic or poisonous gases into the atmosphere. They promote sustainability and drastically reduce environmental pollution and hazards to human welfare. Mg-based alloys contribute to energy conservation and recyclability [11]. 
It is also the sixth most abundant element and current industrial usage is increasing, estimated at $\sim 20 \%$ per annum. It is about $40 \%$ and $75 \%$ lighter than $\mathrm{Al}$ and steel, respectively. This makes these alloys the right fit for biomaterials, green engineering, and light weight structural materials.

Mg-based alloys are laced with some drawbacks especially high susceptibility to oxidation, low melting point $\left(650^{\circ} \mathrm{C}\right)$ during welding $[12,13]$ and poor ambient temperature formability [12-17]. Poor formability at ambient temperatures is attributed to strong basal crystallographic texture from pronounced basal slips under thermomechanical treatment $[14,15]$. The hexagonal closed packed (HCP) structure provides little deformation modes and pathways, accounting to the poor formability in ambient temperatures [14-17]. The low boiling point $\left(1100^{\circ} \mathrm{C}\right)$ and low melting $\left(650^{\circ} \mathrm{C}\right)$ are attributed to the low intermolecular attraction of the atoms, hexagonal closed packed (HCP) structure and associated crystallographic anisotropy [14-17]. The low melting temperature hinders the use of these materials at relatively high temperatures. These alloys are also temperature-sensitive as their strengths and elastic moduli decrease with increasing temperatures [18]. The percentage elongation also increases with increasing temperature up to the melting temperature and then drops drastically to near zero. This has hampered the successful applications of most $\mathrm{Mg}$-based alloys in the industry.

Challenges associated with welding of Mg-based alloys are discussed. These include broadening and bulging of weld pool (particularly for thick workpieces) [13,19], inclusions and contamination of weld zone with porous oxides, undercutting, reduction in mechanical properties (strength-ductility trade-offs) and cracking in the welded joints $[13,19]$. Spattering and discontinuous weld beads are also observed in Mg-based materials [20]. These challenges affect the structural integrity of the Mg-based alloys thus resulting in reduced mechanical properties.

The weldability and structural integrity of $\mathrm{Mg}$-based alloys can be improved using two approaches. Firstly, optimization of different welding techniques and its effects on mechanical properties of Mg-based alloys is essential. These welding methods are mainly fusion and solid-state welding. The method affects the bonding at the fusion zone, heat affected zones and its impact on microstructural and mechanical characteristics of the alloy. Typical fusion welding methods are tungsten inert gas welding (TIG) [21-24], laser or electron beam welding (EBM) [4,25] and hybrid laser-arc welding [26,27]. Friction stir welding (FSW) and resistance spot welding (RSW) [28,29] are the main solid-state welding techniques emphasized in this review for $\mathrm{Mg}$-based alloys $[27,30-32]$. The second approach is the optimisation of process parameters of the welding process to reduce defects and improve weld quality [33,34]. Structural integrity is directly related to the quality of the weldment which is driven by the process parameters $[35,36]$. These include arc travel speed, welding current, electrode feed speed, wire electrode extension, welding voltage, electrode orientation, quality of the shielding gases, electrode diameter and polarity [25-,29, 33-36].
Few reviews have focused on different welding methods of Mg-based alloys, the selection and effects on structural integrity mechanical properties of $\mathrm{Mg}$ alloys [37-40]. Thematic reviews and critical overviews of process variables parameters on the mechanical and microstructural characterization of $\mathrm{Mg}$-alloys are still lacking. A concise overview of processing parameters and its effects on minimizing weld defects and its effects on mechanical properties and structural integrity are presented. This review seeks to fill in the research gap and critically review the advantages of welding metallurgy and prospects for Mg-based alloys.

\section{Methodology and classification of magnesium and its alloys}

\subsection{Literature survey and database}

This review paper is synthesized from carefully selected peer-reviewed conferences, journal articles, authoritative thesis and dissertations. Published journal articles, conference proceedings, research reports, dissertations and theses were collected from various electronic databases. These include Google scholar, Elsevier, Cambridge Core Books and Journals, Wiley Online Library, Scopus, SpringerLink, Taylor and Francis Journals and google search. All articles and conference proceedings included in this review were mainly in English. The keywords used for the search are Mg-based alloys, mechanical properties of Mg-alloys, welding metallurgy, microstructural characterization of $\mathrm{Mg}$ alloys.

\subsection{Physical metallurgy of $\mathrm{Mg}$ and its alloys}

Magnesium alloys are mainly based on $\mathrm{Al}$ and $\mathrm{Al}$-free systems [26,34,41-44]. The Al-based system are designated as AZ (Mg-Zn-Al) and the AM (Mg-Mn- $\mathrm{Al})$ sequence $[12,45,46]$. The low melting $\mathrm{Mg}_{17} \mathrm{Al}_{12}$ intermetallic phase accounts for poor creep resistance with operating temperature below $120^{\circ} \mathrm{C}$. Similarly, there are the AE (Mg-Al-RE) and AXJ (Mg-Al-Ca-Sr) series [45,46]. The AE series are mainly alloyed with rare earth elements with high creep resistance due to precipitates of rare element at grain boundaries $[45,46]$. These alloys operate at temperatures of $\sim 180^{\circ} \mathrm{C}$. The Al-free systems are mainly Zr-containing which are designated as ZK (Mg-Zr-Zn), WE (Mg-Zr-Nd-Y) and QE (Mg-Nd-Zr-Ag), $\mathrm{ZE}$ (Mg-Zr-Zn-RE) and Elektron 21 (Gd - Mg- Nd-Zr) sequence [47]. These alloys have operating temperatures approaching $300^{\circ} \mathrm{C}$. Generally, the effects of various alloying elements on the mechanical and microstructural characteristics of Mg-based alloys are given in Table 1.

Magnesium alloys are produced and used for commercial purposes [26,34,41-44]. Some of these alloys are given in Table 2 showing physical, mechanical and corrosion properties. Some potential areas of applications have been suggested.

\section{Welding types of magnesium and its alloys}

Joining of engineering materials to create intricate and complicated shape is at the heart of engineering design and fabrication of structures. This is being used extensively 
Table 1. Alloying elements on specific properties of Mg-based alloys.

\begin{tabular}{ll}
\hline Alloy element & Casting, melting, mechanical and corrosion behaviour \\
\hline $\mathrm{Ag}$ & Mechanical properties: improves high temperature tensile and creep resistance when alloyed \\
& with rare earth elements. \\
& Corrosion properties: detrimental to corrosion behaviour. \\
& Casting behaviour: increases casting behaviour and lead to microporosity. \\
& Mechanical behaviour: solid solution and precipitation hardening. \\
& Corrosion properties: minimum effect observed. \\
& Casting behaviour: Excellent grain refining and suppress oxidation. \\
& Mechanical behaviour: improves creep resistance. \\
& Corrosion behaviour: poor corrosion resistance. \\
& Casting behaviour: increases evaporation and burning behaviour. \\
& Mechanical behaviour: Solid solution hardening effect, reduces density and increases ductility. \\
& Corrosion behaviour: decreases corrosion resistance. \\
& Casting behaviour: precipitation of fine Fe-Mn precipitates. \\
& Mechanical behaviour: increases creep resistance. \\
& Corrosion behaviour; improves corrosion with Fe in the alloy. \\
$\mathrm{Mn}$ & Casting behaviour: improve castability and reduces microporosity. \\
& Mechanical behaviour: precipitation hardening and solid solution strengthening at both room \\
& and high temperatures improving tensile and creep properties. \\
\hline
\end{tabular}

Table 2. Commercial Mg-based alloys with specific property characteristics.

\begin{tabular}{ll}
\hline Alloy & Characteristics and area of applications \\
\hline AM20 & Good impact strength with appreciable ductility \\
AM50 & Good alloys for high-pressure die castings \\
AS41 & Great creep resistance up to operating temperatures of $150^{\circ} \mathrm{C}$ \\
AS21, AE42 & Easy to weld, intermediate strength alloy and excellent plasticity \\
AZ31 & Alloy with outstanding strength, easy weldability \\
AZ61 & Exceptional ductility at room temperatures, toughness and strength \\
AZ63 & Castings that are both strong and leak-proof for pressure die casting \\
AZ81 & Great alloy for sand and die castings \\
AZ91 & Good castability, easy to weld and creep resistance up to $250^{\circ} \mathrm{C}$ \\
EZ33 & Sand castings, easy to weld and good creep resistant to $350^{\circ} \mathrm{C}$ \\
HK31 & Easy to weld with high proof stress to $250{ }^{\circ} \mathrm{C}$ \\
QE22 & Easy to weld with good proof stress to $300^{\circ} \mathrm{C}$ and creep resistance \\
QH21 & Easy to weld and great resistance to corrosion \\
WE43 & Elevated and ambient temperature strengths \\
WE54 & Pressure-tight castings, good relatively high temperature strength and easy to weld \\
ZC63 & Great sand-casting behaviour, good ambient temperature strength and ductility \\
ZE41 &
\end{tabular}

across various industries for structural application. Joining is grouped under mechanical and liquid-solid state processes. Mechanical joining includes fasteners, bolts and nuts, and screws. There is no phase transformation or microstructural evolution associated with mechanical joints as there is no temperature involvement. Liquid and solid-state joining of parts includes welding, adhesive bonding, brazing and soldering $[48,49]$.

\subsection{Fusion welding}

Fusion welding is the application of heat to join two or more materials or mechanical components by melting to their melting point [50-52]. This technique uses filler or no filler metal depending on the material, the weld design, and the joint assemblage. This process does not require any welding pressure to achieve weldment of great quality 


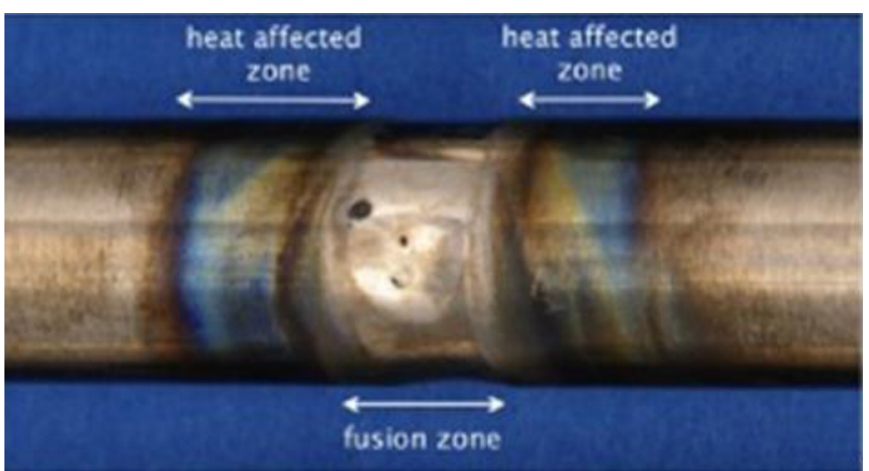

Fig. 1. Different zones on a typical welded metallic structures showing the heat affected zones (HAZ) and the fusion zone [52].

[50-53]. Phase transformation process due to excess heating leads to the formation of a fusion zone (weldment) and the heat affected zone (HAZ) (Fig. 1), adversely or positively affecting mechanical behaviour and structural integrity [52]. The fusion zone is a solidification microstructure made of the deposited metal and the portion of the melted parent or base metal during welding. The HAZ is the area close to the fusion zone and not melted but undergoes microstructural evolution from the extremely high temperatures associated with the welding process [52]. Some of the fusion welding methods include electron beam welding (EBM), arc welding, laser welding, gas metal arc welding (GMAW), and hybrid welding [54].

\subsubsection{Tungsten Inert gas welding (TIG) gas tungsten arc welding (GTAW)}

The TIG welding method requires the generation and application of heat from an electric arc. It may be referred to as gas tungsten arc welding (GTAW). Non-consumable tungsten electrodes are used in the welding process. The adjoining metals are melted together, and the molten pool is shielded in inert gases such as $\mathrm{Ar}, \mathrm{He}$ and $\mathrm{N}_{2}$ to prevent atmospheric contamination. Advantages of using GTAW are the ability to weld with or without a filler metal and one can easily switch between automatic and manual mode (no need for consumable electrodes). This yields solid, clean and aesthetic joints with minimized defects [55]. A major drawback of GTAW is the presence of pores in the welds compromising weld quality and integrity. Coarse grains are also formed in the weldment. These coarse grains are sites for the movement of dislocations hence easy propagation of cracks. This follows the Hall-Petch relation where the grain sizes are inversely proportional to strength. The process is also time consuming compared to other welding methods and require specialized training $[39,56]$.

Grain sizes are critical to improving mechanical properties of alloys and weldments, which underpins the Hall-Petch relation [57-60]. Decreasing grain sizes contribute to enhanced weld quality and is attainable by optimizing welding parameters to control high thermal gradients for grain growth [60]. Welding speeds have significant effects on grain sizes, which affect mechanical and microstructural characteristics [61]. For typical AZ31B alloys, a speed of $135 \mathrm{~mm} \mathrm{~min}^{-1}$ resulted in a tensile strength of $188 \mathrm{MPa}$, which is relatively high for Mg-based alloy [61]. The tensile property is attributed to small grain size and evenly dispersed fine precipitates within the microstructure [43]. Similarly, the tensile strength of LA141 Mg alloy was 95\% of the base metal after welding at a current of $60 \mathrm{~A}$ and speed within the range of 2.8 to $3.2 \mathrm{~mm} \mathrm{~s}^{-1}$ as shown in Table 3 [62]. Postweld heat treatment (PWHT) improved the plasticity of the weld zone by $16 \%$ an improved microhardness profile shown in Figure 2. Using welding voltage of $20-22 \mathrm{~V}$, welding current of 60-120 A and welding speed of $5 \mathrm{~mm} \mathrm{~s}^{-1}$, the AZ91D alloy was welded without cracks in the butt joints [63]. The butt joints had fine grain sizes contributing to the high strength. In the HAZ, hot cracking was observed under the welding bead.

Coarse grains during GTAW are detrimental to mechanical properties [65]. Refinement of grains and other microstructural features such as precipitates, carbides and nitrides improve certain properties as yield and tensile strengths, especially at the weld zone using a magnetic arc oscillation [65]. By placing a magnetic arc oscillator in the welding direction, dendritic microstructures are refined due to the mechanical mixing process in the weld zone. For a AZ31B gas welded alloy, a magnetic oscillatory frequency from 1 to $3 \mathrm{~Hz}$ showed great improvement in tensile properties [66]. Generally, the tensile properties increased gradually with increasing oscillation arc frequency from 1 to $1.5 \mathrm{~Hz}$ and then peaked at $2 \mathrm{~Hz}$ and then a sudden decline was observed for frequencies above 2 to $3 \mathrm{~Hz}$ (Tab. 4). Low oscillatory frequency results in wide weld bead with decreased penetration due to low thermal and mechanical agitations. The transition of fine grains to coarse and elongated grains at relative low oscillation frequency and above $2 \mathrm{~Hz}$ accounts for the poor tensile properties. The highest tensile properties recorded at $2 \mathrm{~Hz}$ are characterized by fine grains and evenly distributed precipitates.

Dynamic grain refining using ultrasonic vibration assisted treatment is used to improve mechanical properties of weld joints [67-70]. Thus, refining the grain sizes improve bond strength of the welds which improves mechanical properties (e.g., tensile and yield strengths) [71]. Similar grain refinement was carried out on AZ31 Mgalloy under different vibration direction, vibration amplitude, and groove angle [68]. The welding was done at $20 \mathrm{~cm} / \mathrm{min}$ and at $100 \mathrm{~A}$ with the grain size decreasing significantly under the vibration conditions. Effects of vibration parameters on the phase proportion of the intermetallic $\beta-\mathrm{Mg}_{17} \mathrm{Al}_{12}$ at the welding zone was marginal but with relative increased micro-hardness and tensile properties (Fig. 3) [68]. Vibration also affects the weld thickness. The impact of vibration on microstructure and mechanical properties of the weld joint are determined by the amount of energy introduced. This is also dependent on the amplitude, orientation of the vibration, depth, and groove direction.

Coarse grains, residual melting and stress cracking are detrimental to tensile properties in the weld zones. These are due to the thermal peaks and troughs welding in the welding pool and base material. The intensity of the 
Table 3. Tensile properties of LA141 alloy welded plates and base metal before and after heat treatment [64].

\begin{tabular}{llllll}
\hline Specimen & Heat treatment & $\begin{array}{l}\text { Tensile strength } \\
(\mathrm{MPa})\end{array}$ & $\begin{array}{l}\text { Yield strength } \\
(\mathrm{MPa})\end{array}$ & $\begin{array}{l}\text { Elongation } \\
(\%)\end{array}$ & Fraction location \\
\hline \multirow{3}{*}{ Base metal } & Before & 161 & 159 & 23 & Middle \\
& After & 127 & 114 & 26 & Middle \\
\multirow{2}{*}{ Welded plate } & Before & 153 & 150 & 8 & HAZ \\
& After & 124 & 113 & 16 & HAZ \\
\hline
\end{tabular}

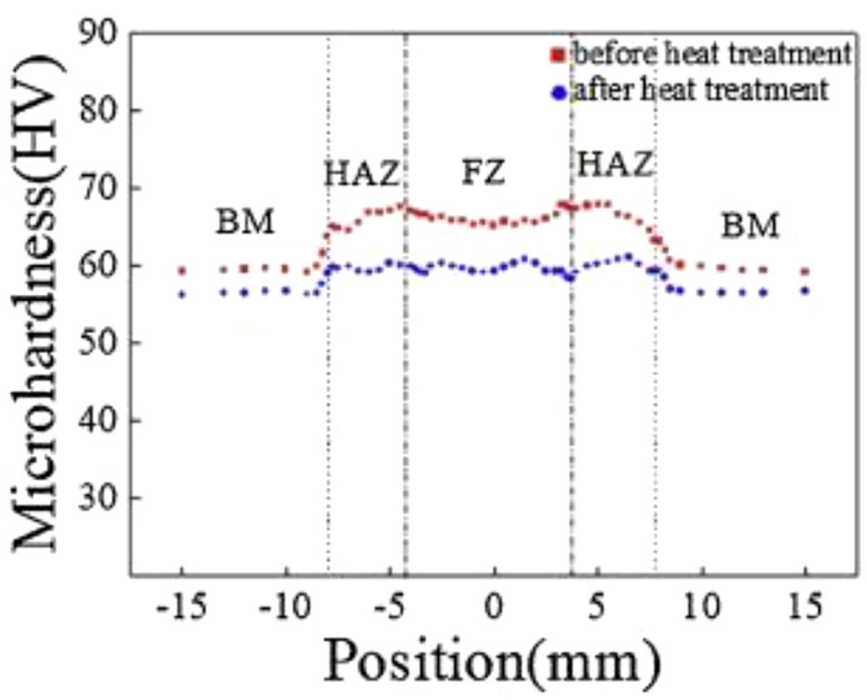

Fig. 2. Hardness profile of LA141 alloy welded joint before and after heat treatment [64], reuse with permission from Elsevier.

residual melting and the stress cracking close to the weld are very high [72]. Finite element modelling (FEM) are used to study the impact of residual melting and stress cracking on low residual stresses [73]. Generally, fusion of the low melting point eutectic $\beta-\mathrm{Mg}_{17} \mathrm{Al}_{12}$ phase in the welded seam contribute to the overall reduction in tensile strength. These intermetallic phases promote stress cracking under very low residual stress regime. Similarly, FEM with infrared radiation is used to investigate the welding temperature and cooling curves of AZ31B alloy weld joints [74]. The emissivity of the AZ31Mg-alloy was $\sim 2$.

\subsubsection{Metal inert gas welding}

Metal inert gas welding (MIG) is among the common form of welding metals. It is also known as gas metal arc welding (GMAW) which requires the melting and solidification of base metals together with a wire electrode [63,76,77]. Improvement initiatives for Mg-based alloys are to minimize porosity rate, improve mechanical properties of joints, understand mechanisms impacting porosity and other weld defects [76]. Minimization of pores after GMA welding of AZ31B Mg-alloy sheets was achieved by increasing welding speed above $8.3 \mathrm{~mm} \mathrm{~s}^{-1}$ and wire feeding rates above $110 \mathrm{mms}^{-1}[77]$. These parameters increased the rate of solidification due to lack of evaporation of $\mathrm{Mg}$ and $\mathrm{Zn}$ elements associated with low welding rates below $8.3 \mathrm{~mm} / \mathrm{s}$. There is also short time for the formation of unwanted bubbles associated relatively high welding speeds. Bubbles in the weld zone compromise structural integrity of the weld adversely affecting mechanical properties. Thus, weld speed and wire feeding rates are critical parameters which should be optimized to improve mechanical properties and structural integrity of welds of $\mathrm{Mg}$ alloys.

The process parameters affecting weld quality and mechanical properties are presented [63,76,78]. Low welding speed improves the cracking resistance of MIG welded AZ91D Mg alloys [63]. Solidification cracking was noted in the HAZ at welding speed of $\sim 5 \mathrm{~mm} \mathrm{~s}^{-1}$. Such low welding speed is generally accompanied with intense heat and high thermal stresses resulting in evaporation of vital elements with associated crack initiation [63,76]. High welding speed leads to low applied heat and low thermal stresses. This improves resistance to crack propagation during MIG welding of AZ91D Mg alloys [63]. The welding speed for typical Mg-alloys is estimated to range from 400 to $1400 \mathrm{~mm} / \mathrm{min}$ for MIG, which could lead to great properties of weldments [77]. Another process parameter affecting weld quality and mechanical properties of AZ31B $\mathrm{Mg}$ alloy is pulse current [79]. Defects such as inclusions in the weld beads, pores, micro segregation and micro-cracks are minimized due to the pulsed rework current and a negative pulse current. Based on the pulse current, tensile strength up to $\sim 97 \%$ of the base metal and elongation up to $\sim 78 \%$ of the weld bead of AZ31B Mg-alloy was observed. These process variables can be highly optimized to improve the mechanical and microstructural features.

The impact of process parameters on $\mathrm{Mg}$ alloy using DC double pulse MIG welding is discussed [80]. This controls the melting pool as the time is shorten, reducing the weld width and penetration depth. Low frequencies also prevent disorderliness as heat input is moderated. The penetration of large weld beads and great appearance is observed with continuous increase of current (either low or high pulse) until maximum allowable D-value of $60 \mathrm{~A}$ is attained. Increasing pulse current above maximum allowable D-values increase arc agitation of the molten pond, leading to spattering and disorderliness. The microstructures of the weldment is a mixture of $\alpha-\mathrm{Mg}$ solid solution and $\beta-\mathrm{Mg}_{17} \mathrm{Al}_{12}$ intermetallic typical of $\mathrm{AZ31B}$ alloy [72]. Uniform and finer equiaxed grains were in the $\mathrm{FZ}$ compared to the parent metal. This is due to the strong stirring effect of the double pulse MIG welding arc. The UTS of the fusion 
Table 4. The effect of arc oscillation frequency on the properties of AZ31B Mg-alloy TIG welded joints [75].

\begin{tabular}{lllllll}
\hline $\begin{array}{l}\text { Arc oscillation } \\
\text { frequency }\end{array}$ & $\begin{array}{l}\text { Yield strength } \\
(\mathrm{MPa})\end{array}$ & $\begin{array}{l}\text { UTS } \\
(\mathrm{MPa})\end{array}$ & $\begin{array}{l}\text { Elongation } \\
(\%)\end{array}$ & $\begin{array}{l}\text { Notch tensile } \\
\text { strength (MPa) }\end{array}$ & $\begin{array}{l}\text { Notch Strength } \\
\text { ratio (NSR) }\end{array}$ & $\begin{array}{l}\text { Joint efficiency } \\
(\%)\end{array}$ \\
\hline 1 & 163 & 206 & 6.8 & 161 & 0.78 & 75 \\
1.5 & 175 & 221 & 7.2 & 172 & 0.77 & 80 \\
2 & 192 & 248 & 7.6 & 188 & 0.75 & 91 \\
2.5 & 154 & 193 & 5.2 & 159 & 0.82 & 70 \\
3 & 150 & 186 & 4.8 & 155 & 0.83 & 68 \\
\hline
\end{tabular}
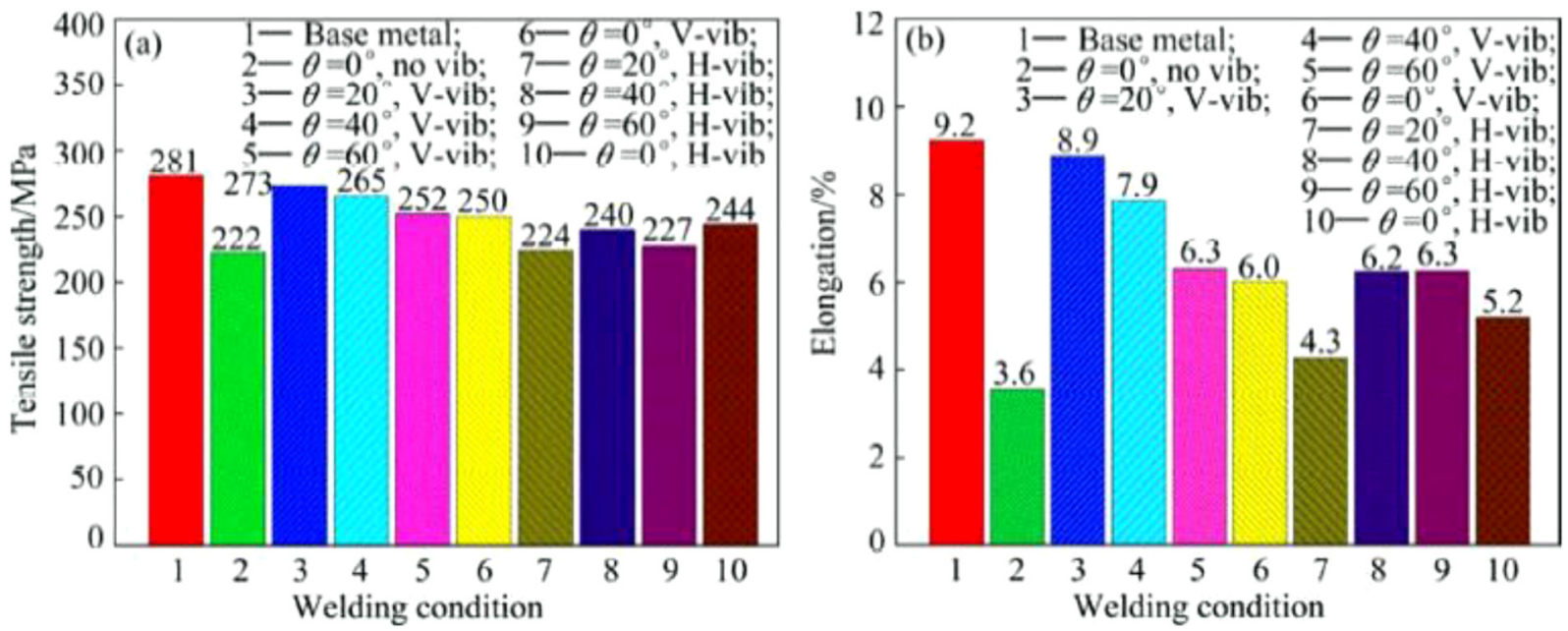

Fig. 3. Vibration parameters on: (a) UTS and (b) elongation of AZ31 Mg weldment [68], reuse with permission from Elsevier.

Table 5. Effect of welding speed on cooling rate, grain sizes and mechanical properties of AZ61 alloy [96].

\begin{tabular}{lllllll}
\hline $\begin{array}{l}\text { Welding speed } \\
(\mathrm{mm} / \mathrm{min})\end{array}$ & Cooling rate $\left(\mathrm{Ks}^{-1}\right)$ & $\mathrm{D}(\alpha-\mathrm{Mg})(\mu \mathrm{m})$ & $\begin{array}{l}\mathrm{D}_{\beta-\mathrm{Mg} 17 \mathrm{Al12}} \\
(\mu \mathrm{m})\end{array}$ & $\begin{array}{l}\mathrm{V}_{\mathrm{f} \beta \text {-Mg17Al12 }} \\
(\%)\end{array}$ & $\begin{array}{l}\sigma_{\mathrm{UTS}} \\
(\mathrm{MPa})\end{array}$ & $\begin{array}{l}\sigma_{\mathrm{Y}} \\
(\mathrm{MPa})\end{array}$ \\
\hline $\mathrm{BM}$ & - & - & - & - & 285 & 278 \\
1800 & 8287 & 8.8 & 1.3 & 6.02 & 143 & 121 \\
2200 & 12364 & 7.4 & 1.1 & 6.08 & 225 & 173 \\
2500 & 15963 & 6.7 & 0.8 & 6.19 & 236 & 178 \\
2800 & 20020 & 5.9 & 0.6 & 6.47 & 268 & 195 \\
\hline
\end{tabular}

NB: BM - Base material, D - grain sizes, $\mathrm{V}_{\mathrm{f}}-$ volume fraction.

zone was $234 \mathrm{MPa}(96 \%$ of the $\mathrm{BM})$, whereas elongation was $11 \%$ ( $75 \%$ of BM). The reduction in property were due to the precipitations and volume defects in the fusion zone acting as stress concentration points and crack initiation sites. By optimizing the process parameters, mechanical properties and weld quality can be improved.

\subsubsection{Electron beam welding}

Electron beam welding (EBW) uses dense stream of high velocity focused electron beams impinging on the materials to fuse materials to be joined together until fusion $[51,81,82]$.
An electron gun is the source of the electron beam composed of tungsten cathode and high vacuum anode. Electron beams are focused on the material in such a way that the capacity of the alloy to dissipate the electrons by conduction is overcome. This heat input then leads to vaporization, melting and ionization. The process is intricate, and the welding quality depend on the welding process parameters. The accelerating voltages range from 30 to $175 \mathrm{kV}$, whereas the beam current ranged from 50 to $1000 \mathrm{~mA}$ depending on the type of $\mathrm{Mg}$ alloy. The EBW process is generally used for metals that are difficult to weld and when there is repeatability. Other process parameters include welding speed, spot size and vacuum level (below $10^{-3}$ torr). By 
keeping the beam current below specific thresholds (dependent on alloy), vaporization is prevented and thus a keyhole is not created. Thus, the welding heat input and the beam current are significant parameters in enhancing the shape and the structural integrity of the weld and the keyhole stability [83].

Changes in process variables affect quality and geometry of weld joints $[51,84,85]$. Deep penetration and surface thermal effects are associated with electron beam welding for $\mathrm{AZ} \mathrm{Mg}$ alloys [84]. The beam width in EBW is used to determine the force of the field depth which critical to welding process $[51,84]$. Sharp focused electron beam increase the welding energy density and the penetration depth $[51,84,85]$. The FZ has poor mechanical properties (hardness and strength) than the base metal and heat affected zones [84]. These are associated with coarse grains and porosity due to solidification of the fusion zone $[51,86,87]$. The variation in the electron beam spot width greatly improved the heat propagation characteristics resulting in good quality weld joint [88].

The electron beam currents have great effects on the rate of penetration [51]. This leads to a fine-equiaxed microstructure with significant improvement in the tensile properties of the weld joints.

\subsubsection{Laser welding}

Laser welding is the application of beam of lasers to join metals or thermoplastics together [12]. It is a process that requires concentration of the heat source and relatively high welding speeds. The keyhole and conduction processes are the main modes of laser welding [12]. Welding in the conduction mode is carried out at power densities less than $105 \mathrm{~W} / \mathrm{cm}^{2}$. The laser beam is absorbed mainly at the surface with negligible penetration power. Thus, conduction limited weld has very high width to depth ratio. The keyhole laser welding mechanism occurs at relatively highpower densities above $105 \mathrm{~W} / \mathrm{cm}^{2}$. By introducing laser beam of power densities of $\sim 106 \mathrm{~W} / \mathrm{cm}^{2}$, the spot at which the laser is concentrated melts and vaporizes before any conduction can take place. The focused beam, by penetrating the workpiece forms a cavity, a keyhole filled with ionized vapour, forming plasma.

Effective and good weld joints from laser welding is affected by the physical and mechanical properties of the metal being joined. Mg-based alloys have strong oxidizing tendencies, low absorptivity of laser beams, low viscosity, high thermal conductivity, low melting points, high solidification shrinkage and high affinity for hydrogen in the liquid state. Laser welded Mg-alloys are prone to unstable weld pool $[89,90]$, loss of alloying element of $\mathrm{Zr}$ and $\mathrm{Al}$ due to vapourisation and undercut [80,91,92].

A major review of welding of Mg-alloys based on this method was done in 2006 [12]. Emphasis was on the use of $\mathrm{CO}_{2}$ and Nd-doped Y-Al garnet as laser source with wavelengths of 10.6 and $1.06 \mu \mathrm{m}$. The use of high powder density on the workplace has been emphasized for keyhole welding. Generally, the effect of laser power, focal plane position, welding speed and surface preparation, shielding gas, filler metal and process tolerance on the quality of laser welded $\mathrm{Mg}$ alloys were reviewed [12]. Filler metal was identified as the critical factor which is influenced by high power and low welding speed. The challenge is there are few filler wires developed to aid the welding process in laser welded Mg-alloys.

Optimizing process parameters are critical to improving laser welded $\mathrm{Mg}$ alloys mechanical properties [93-95]. The tensile strength of welded joints achieved $88 \%$ of the base metal at a welding speed of $10 \mathrm{~m} \mathrm{~min}^{-1}$ using a $3 \mathrm{~kW}$ fibre laser [93]. Generally, there is grain size reduction, Similarly, the tensile and fatigue properties and the microstructural evolution of fibre laser welded AZ31B-H24Mg alloy and the influence of diverse welding speed have been reported [95]. The welding process led to the formation of $\mathrm{Mg}_{17} \mathrm{Al}_{12}$ eutectic particles, equiaxed and columnar dendrites around the fusion zone boundary and the recrystallization of grains in the thermal zone. The fusion zone had the least hardness, resulting in decreased yield and fatigue strengths. This is mainly due to the differential solidification, grain coarsening and defects due to entrapped gases, oxide inclusions, cracking, depletion of alloying elements and porosity within weld microstructure have effects on structural integrity [12].

Relatively high welding speeds ranging between 30 and $120 \mathrm{~mm} / \mathrm{s}$ led to small melting and fusion zones in the laserwelded joints of Mg-based alloys [94,95]. This is accompanied by reduced grain size resulting in high yield strengths and good fatigue life with relatively low strain-hardening [95]. On the other hand, high welding speed (give the range) and low power levels (give the range) promote good penetration and an active flux with good effects on overall weld quality [28]. The influence of welding speed and laser power on mechanical properties and microstructure of $2.0 \mathrm{~mm}$ thick ZK60 sheets have been studied [95]. When welding speed was raised from 1 to $4 \mathrm{~m} \mathrm{~min}^{-1}$, tensile strength and elongation initially increased but then decreases as welding speeds exceeded $4 \mathrm{~m} / \mathrm{min}$. The welding speed is a critical parameter for laser welded AZ61 and its effects on the cooling rate, grain sizes, volume fraction of phases and mechanical properties as shown in Table 5. Generally, the mechanical properties (UTS and yield strength) of the base metal are higher than the fusion (FZ) and HAZ. This is due to the variation in microstructure and its associated grain sizes and volume fraction. The microstructure of extruded AZ61 was uniform and equiaxed with intermediate grain size of $39 \mathrm{~mm}$, whereas the fusion zone had dual equiaxed dendritic $\alpha-\mathrm{Mg}$ (soft) and dispersed intermetallic $\beta-\mathrm{Mg}_{17} \mathrm{Al}_{12}$ particles with average grain sizes decreasing with increasing welding speed. The fusion zone after solidification is more a cast structure in contrast to the base metal, which is wrought, a contributing factor of the observed higher strength than the FZ and HAZ. The HAZ undergoes heat treatment hence coarse grain sizes are sometimes observed [96]. Similar trends have been reported for fatigue strength between FZ, HAZ and BM [95].

Volume and line defects such as precipitates, shrinkage pores and inclusions are detrimental to quality and mechanical properties of laser-welded joints. The main volume defect is pores formed, pre-existing one during differential solidification and entrapment of various gases $[11,27,97]$. For instance, pores formed due to the presence and entrapment of hydrogen $[11,27,97]$. Concentrated heat 

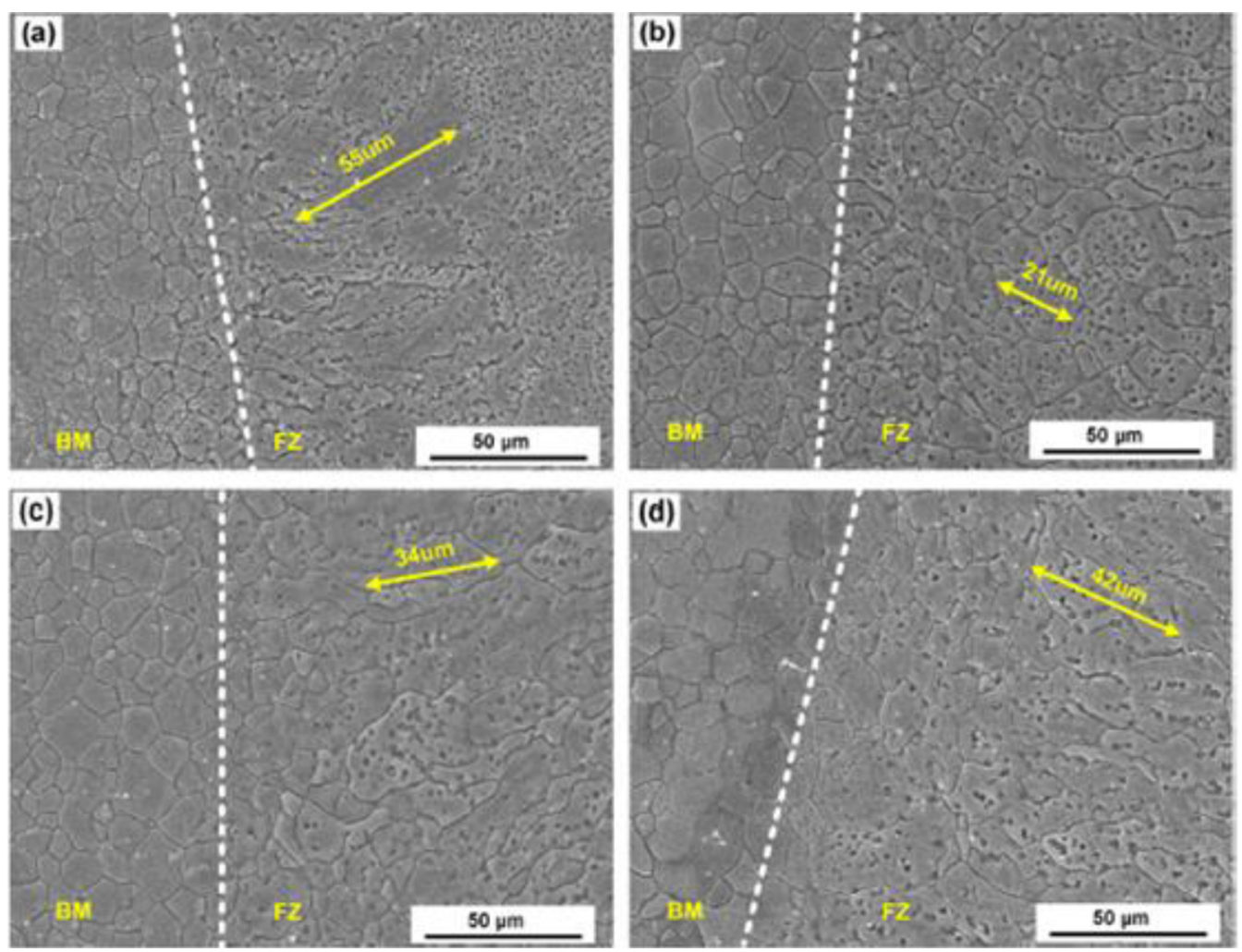

Fig. 4. SEM images of the weld microstructure neighbouring the fusion line, (a) excluding oscillation of beam, (b) $f=50 \mathrm{~Hz}$ and $r=0.5 \mathrm{~mm}$, (c) $f=50 \mathrm{~Hz}$ and $r=1 \mathrm{~mm}$, (d) $f=75 \mathrm{~Hz}$ and $r=1 \mathrm{~mm}$, BM indicates the base metal, FZ indicates the fusion zone [92], reuse with permission from Elsevier.

on the base metal can also lead to keyholes which are unstable and detrimental [11,98-100]. Low vaporization of some alloy elements can also be detrimental to the mechanical properties and structural integrity of welds [101].

Minimization of the defects in welds is critical to structural integrity [97]. Ways to reduce pore formation in Mg-based alloys include optimizing the $\mathrm{Mg}$ content and processing parameters [97]. The use of high welding speed leads to narrow fusion zones and this speeds up the solidification process, thus few and small pore sizes are observed in the weld bead [102]. In some cases, the welding is preceded by preheating, a form of heat treatment that effectively reduces sizes of pre-existing pore and prevent new ones from nucleating at the interconnection of two intersected sheets of AZ31B Mg alloys [103]. Optimizing processing parameters have also reduced the porosity of fusion zones. For instance, fibre laser welding of ACM522 $\mathrm{Mg}$ alloy resulted in increased depth of penetration and increased weld bead with increased laser intensity [104]. The microstructure of the weldment were refined and the porosity of the weldment decreased with increasing welding speed [105].

Oscillating frequency is another process parameter that affect the quality of laser welded joints of $\mathrm{Mg}$ alloy. Low oscillating frequency $(\sim 50 \mathrm{~Hz})$ with welding speed of
$33 \mathrm{mms}^{-1}$ and beam oscillating diameters of $0.35 \mathrm{~mm}$ improved aesthetic qualities of the weld with remarkable mechanical properties [106]. This is shown in the microstructures in Figure 4. The beam oscillation showed continuous columnar grains at the fusion, whereas non continuous fusion outline is associated with regions without the beam oscillation effect.

Also, Gao et al. [107] in their study, assessed the effect of process variables on the AZ31 Mg alloy properties, the authors observed that an increase or decrease or any change within the beam oscillation frequency immediately affected the alloy mechanical characteristics. By reducing the gradient, the beam swing splits the expansion of the columnar grains on the welding edge. The broken dendrites area unit then pass through robust convection and eddy effects into the weld centre, which act as nucleation areas for the equiaxed dendrite. In their research, Lei et al. [108] found that the ultrasonic laser welding technology used in joining AZ31B Mg with a welding velocity of $1.0 \mathrm{~m} \mathrm{~min}^{-1}$ and a focal length of $192 \mathrm{~mm}$ significantly reduced its weld porosity to less than 1 percent. In addition, the number of nucleation particles increases when ultrasonic vibration is used, thus increasing the number of refined grains during the weld pool crystallization process, which enhances the mechanical properties of the welded joint. The mean area of grain in the weld centre is thus reduced from $359.9 \mu \mathrm{m}$ to $213.7 \mu \mathrm{m}$. 
Table 4 and 5 shows that the majority of AZ31 and AZ61 Mg alloys have been investigated [84,109-111]. The different welding process parameters considered were equally indicated. The parameters for these operations are similar. Researchers investigated the effect of process parameters such as welding speed, vibration frequency, welding current, welding voltage, vibration frequency, focal length of the focusing lens on the properties of the joints such as the mechanical properties (tensile properties, bend properties, fatigue strength and microhardness) and the thermal effect [25-29,33-38].

\subsubsection{Summary on fusion welding of $\mathrm{Mg}$ alloys}

The above studies show that various approaches have been considered to improve the microstructural and mechanical properties of welded $\mathrm{Mg}$ alloys. However, there are various process parameters affecting the structural integrity of the welds. The microstructural and mechanical properties are dependent on these process parameters ranging from the welding speed, rotation rate, travel speed, welding current and vibration frequency. The difficulty is that optimizing one could compromise the other. Thus, the effects of very few processing variables on microstructural and mechanical properties of $\mathrm{Mg}$ alloy welds have been investigated. There is the need to use computational modelling coupled with numerical simulations to understand the overarching effects of these parameters [85,112-114]. This method will be faster, less expensive, and not lengthy as the Edisonian approach. Data collected can be validated with some experimental work.

\subsection{Hybrid welding}

Hybrid welding refers to procedures in which laser welding and other welding methods are consolidated in a conventional welding zone with the goal of achieving what a singular welding procedure could not accomplish by adding synergy of the advantages of welding procedures, thus removing their weakness. Due to advantages such as its capacity to produce a concentrated, deep and narrow welding pool with precision without the side effects of heat deformation, laser welding has been anticipated to offer promising outcomes in the welding of $\mathrm{Mg}$ alloys [115]. On the other hand, Laser welding systems are more expensive, and the electrical effectiveness of most laser welding process systems is poor. By the way of illustration, laser welding procedures displays a reduced capacity to bridge gaps thus calling for extra task in ensuring the workpiece alignment and maintaining accurate surface preparations thus adding to the overall cost of production. In contrast to this, arc welding techniques displays excellent strength in the weakness of laser welding as it displays an increased capacity to bridge gaps and an enhanced electrical efficiency [116]. For example hybrid laser beam and electrical arc welding resulted in increased welding speed and depth of penetration as well as improved gap bridging and process stability [117].

The idea of a laser/arc hybrid welding technique was first proposed in the late 1970's [118], the schematic illustration of the process is as shown in Figure 5. The quest to develop a better hybrid system was carried out by

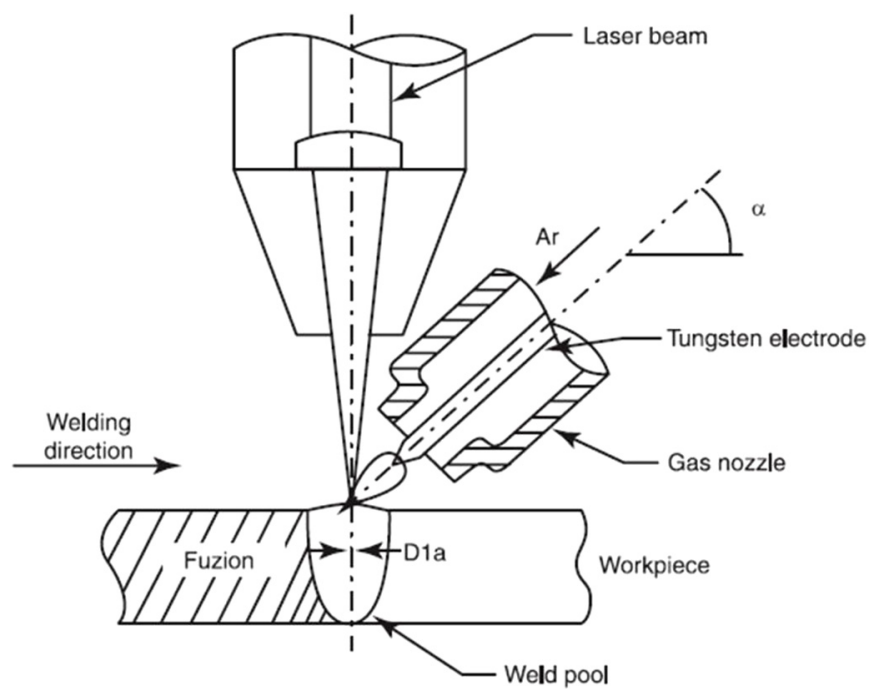

Fig. 5. Schematic diagram of Laser-TIG hybrid laser welding [118], reuse with permission from AIP Publishing

Japanese researchers where they established different techniques and correlating technologies, but there was a setback as these methods were not economically viable [119]. In the early 1990s, with the relentless effort of the researchers, there was a headway of engaging high voltage laser beam as the primary heating source while making the use of electric arc as the subsidiary power source [120,121].

New initiatives and development in TIG have some drawbacks. This includes high cost of maintenance and the occurrence of flaws such as porosity and cracks in the weld zone. These defects are not peculiar to the modified welding techniques in any way though hybrid laser welding was designed for satisfactory industrial usage [122] [174]. Notwithstanding, there is increase usage of hybrid welding of various materials in the 21st century including LaserMIG [123], Laser-Plasma [124] and Laser Double arc welding [122]. The Laser-TIG and GMAW-GTAW hybrid welding techniques were applied to the welding of $\mathrm{Mg}$ alloys recently [125].

\subsubsection{Laser-tungsten inert gas (laser-TIG) hybrid welding}

The efficiency of welded joints for thin plates is directly improved by increasing welding speed [102] Hybrid welding of laser-tungsten inert gas (TIG) is a new technique for high speed welding [145]. In previous research, fusion welding methods such as arc welding and low power laser beam welding were used, but the welding speed was slow [149-151]. Laser tungsten inert gas hybrid welding is a modern highspeed magnesium alloy welding process. A few useful studies have been performed on laser-TIG hybrid welding of $\mathrm{Mg}$ alloys. Most welding rates, however, were below $2000 \mathrm{~mm} / \mathrm{min}$ [152]. By increasing the welding speed from 2000 to $6,000 \mathrm{~mm} / \mathrm{min}$, Li et al. [145] sought to examine the impact of welding rates on the microstructure and mechanical characteristics of high-speed welding through hybrid welding of AZ61 Magnesium alloy with laser-TIG 
technique. With the optimum welding speed of approximately $6000 \mathrm{~mm} / \mathrm{min}$, faulty free welds were achieved. As welding speed increased rapidly, both the linear energy and average grain size decreased, so fully penetrated joints could be obtained at welding speed without macroscopic porosities or cracks. As the welding speed rises, the microhardness of the welded fusion zone increases exponentially. It was also observed that the mode of fracture differs between ductile and brittle fractures, and the traditional intergranular fractures.

\subsubsection{GMAW-GTAW hybrid welding}

The impacts of several welding process factors on weld production, such as wire extension, tungsten electrode distance, bypass current, and the workpiece, have been assessed [147]. The optimal forming weld parameters are 225 A current, 140 A bypass current, $21 \mathrm{~V}$ welding voltage, $2.8 \mathrm{~m} \mathrm{~min}^{-1}$ welding speed, and $5 \mathrm{~mm}$ between the end of the tungsten electrode and the workpiece. Hybrid GMAWGTAW welding is a high-speed welding technology with high consistency and excellent forming of $\mathrm{Mg}$ alloys and welding bead. The application of TIG and a MIG hybrid system are stable in MIG arcs, thus these hybrid welding techniques can be turned into a high quality and efficiency new welding process. [125].

\subsection{Solid state welding}

Solid-state welding procedures involve joining of two metals without the application of heat $[48,49]$. However, heat is generated from the contact surfaces due to the movement of a fixed component part relative to a moving one. This approach is mainly driven by applied pressure and any applied temperature comparatively lesser than the melting point of the mating alloys [48]. The mechanism of bonding is by diffusion of interfacial atoms. The main advantage of SSW is lack of typical weld defects and porosity as observed in the conventional fusion welding techniques. Any phase transformation due to microstructural evolution is negligible due to little or no heat applied during welding. The surface finish and mechanical properties at the weld joints are better than most conventional fusion methods. The main disadvantage is the difficulty in joining more than two components at a time. There is also the need to fill very wide root gaps since it does not require the use of filler materials [153]. There is no melting involved in SSW and weld appearance are great with improved mechanical properties at the weld joint [49].

The SSW technique is classified under different categories. These include cold welding, ultrasonic welding, roll welding, forge welding, pressure welding, friction welding, diffusion welding, explosion welding, and friction stir welding [154]. Friction stir welding (FSW) is widely use as it is flexible and allows for all sorts of metals to be jointed. For instance, soft and difficult to weld metals like $\mathrm{Mg}, \mathrm{Al}, \mathrm{Cu}$ and $\mathrm{Zn}$ are welded with good mechanical properties and with low defects. Other SSW techniques such as roll welding, friction welding and explosive welding have also received some attention, but with some drawbacks. These include causing severe injuries and air pollution [155].

In this review, emphasis is on friction stir welding which is discussed in the next section. The interplay between processing parameters and microstructural features are briefly discussed. Relevant mechanical properties are explained based on the evolution of microstructural features such as grain sizes across the different zones. This is done to understand the suitability for specific engineering application.

\subsubsection{Friction stir welding (FSW)}

Friction stir welding is non-fusion solid state welding process. It uses a quasi-consuming, rotating tool with a pin, extending across the weld line from a wider shoulder to join metals together $[49,156]$. The weld is created by sequential spinning and forward movement of the instrument pin along the weld line, inducing friction and strong plastic deformation at temperatures below the melting point of the adjoining metals [156]. The process does not have welding defects such as shrinkage, hot fracturing and porosity, significantly reduces the thermal stresses induced in the metals [49,156]. A typical friction stir welding process is shown in Figure 6 [157].

Two main classes of input parameters affect the quality of FSW welds [158-160]. These are process variables and tool parameters. The process variables include the rate of rotation, welding speed (tool travel rate), plunge depth and the downward force. The tool parameters are tool pin profile, tool design, tool altitude tilting and the dimensions of the tool. The final surface morphology, mechanical and microstructural features of the joint are significantly influenced by the input parameters. Similarly, factors such as the root gap between the materials, thickness of materials, dwell time of the tool, temperature, and humidity are critical to weld integrity and appearance [161].

The effect of input parameters results in four distinct zones in a typical FSW joints $[42,157,161]$ and is illustrated schematically in Figure 6c [157]. The zones are stirred zone (SZ) or nugget zone (NZ), thermo-mechanically affected zone (TMAZ), heat affected zone (HAZ) and the base metal (BM) zone. Due to difference in applied frictional heat and the flow of the material during welding, different grain structures and features are observed. This results in differences in mechanical properties at these zones. Distinct features of these zones are discussed further.

\subsubsection{Stirred zone (SZ) or nugget zone (NZ)}

The stirred zone (SZ) is recrystallized dynamic area in the middle of the weld area (Fig. 6c). Frictional heat and plastic deformation due to direct contact between the tool and the workpiece led to remelting, resulting in fine grains $[42,161]$. The $\mathrm{SZ}$ which is characterized by recrystallization can be identified by onion rings as a result of frequent rotation movement of the tool pin on the soldered surface $[42,161]$. 


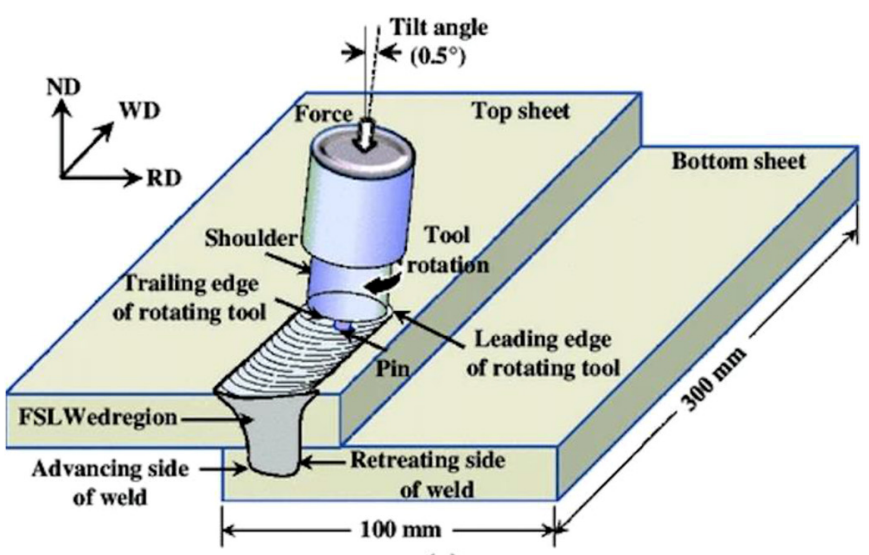

(a)

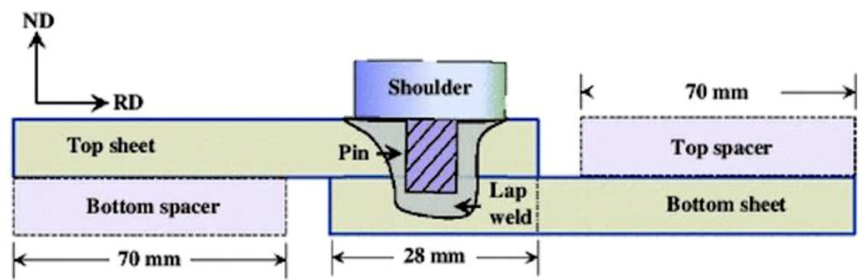

(b)

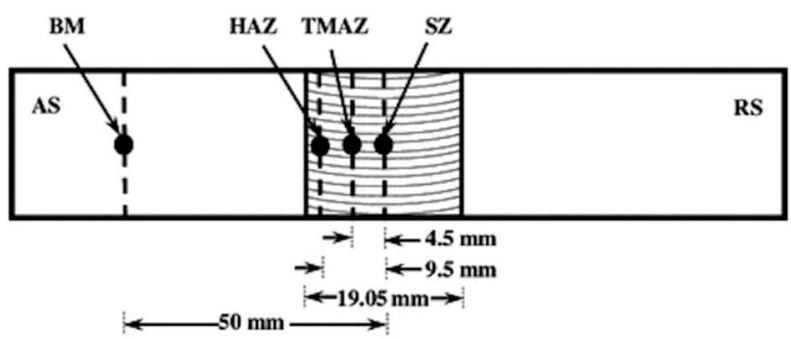

(c)

Fig. 6. Schematic diagram showing (a) a friction stir lap welding (b), (c) and (d) are side view of an overlapped joint with dimension and (d) top view of tensile lap shear testing c [157], reuse with permission from Springer Nature.

\subsubsection{Thermo-mechanically affected zone (TMAZ)}

The TMAZ is the area between the stir zone and the heat affected zone. It undergoes relatively high temperature change during the welding thermal cycle, and experience minor plastic deformation with no recrystallization [42,161]. Generally, relatively coarser grains are observed in the TMAZ compared to the SZ. This is mainly attributed to the initial microstructures of the $\mathrm{Mg}$ alloy and the coarseness is due to the minor plastic deformation triggered by the movement and plunging of the tool shoulder (Fig. 6b) [42,161].

\subsubsection{Heat affected zone (HAZ)}

In the HAZ the tool and the metal are not linked directly. In this zone, the metal is not stirred or rubbed by the pin. There is no distortion in this area, but the metal is influenced by the thermal welding which leads to a few changes in the microstructure. The grains are near the base metal in this area, but are somewhat smaller $[42,161]$.

\subsubsection{Base metal (BM)}

The BM is the base or parent material. Considering it is farther from SZ and TMAZ, microstructural features do not change as there is negligible effects of mechanical and thermal cyclic stresses to induce any significant plastic deformation. The starting microstructure of a typical $\mathrm{Mg}$ alloy defines the grain sizes in this zone. Typical coarse grains are expected in this zone compared to the SZ and TMAZ, which then decreases steadily across TMAZ and SZ [42,161]. However, there are results that suggest small grain sizes at BM with coarse grain observed for TMAZ and SZ [157]. This is generally affected by tool rotational and welding speeds.

\subsubsection{Effect of input parameters on microstructure and mechanical properties}

Input parameters lead to changes in microstructural evolution and mechanical properties of friction stir welding of Mg-alloys [162-166]. The use of Bobbin tool friction stir welding (BTFSW) on ZK60 Mg alloy resulted in significant grain refinement and disintegration of the $\mathrm{Mg} 4 \mathrm{Zn} 7$ precipitate in the stir zone (SZ) [167]. Extensive thermal softening at the SZ resulted in lower the yield strength of the BTFSW joints than that of BM. This is mainly attributed to grain refinement influenced by the welding speed of 300-400 mm/ min. Similarly, carefully selected rotational speed of 300 $800 \mathrm{rpm}$ and constant tool speed of $500 \mathrm{~mm} / \mathrm{min}$ using a displacement-controlled type of FSW on ZK60 Mg alloy [168]. The UTS of the joint was $91-95 \%$ of the BM. The input parameters resulted in refining the microstructure with $\mathrm{Zr}$ rich precipitates and bimodal recrystallized grains sizes ranging from 0.6 to $1.5 \mu \mathrm{m}$ in the $\mathrm{SZ}$. The dissolving of $\mathrm{Mg}-\mathrm{Zn}$ precipitates at the $\mathrm{SZ}$ as a result of the welding speed was accompanied by extensive thermal softening [169].

The effect of the heat input and the rotational speed of FSW joints of AZ61 Mg alloy was studied [164]. The heat input was determined to be commensurate to the welding speed and indirectional proportional to the rotational speed. A welding and rotational speed of 2 is undesirable for AZ61 alloy joints due to the formation of tunnel, cavity, and flash defects in the weld region. Grain refinement of the SZ was attributed to reduction in tool rotational speed and vice versa. This is also supported for other $\mathrm{Mg}$ alloys [154,170].

Inadequate penetration, kissing bound, tunnel defects, worm hole, and lazy S are defects associated with FSW [171]. To limit the occurrence of these defects, hybrid FSW are being used [172]. These include using secondary energy sources such as laser beam, inductive coil [173,174]. However, these secondary energy sources do have demerits, which leads to weld defects. Ultrasonic approach, there by or which is being used as it promotes the flowability of the material, thereby or which increasing the rate of penetration with negligible increase in peak temperature with great weld joints [175]. Ultrasonic assisted FSW also contributes to continuous frequency oscillation, resulting in high-quality weld joints. The ultrasonic vibrations enabled the formation of very fine grains in the SZ thereby increasing its hardness and strength when compared to other regions [172]. The fine grain sizes increase the grain boundaries hindering the dislocation motion, thereby 
Table 6. Fusion welding process with parameters.

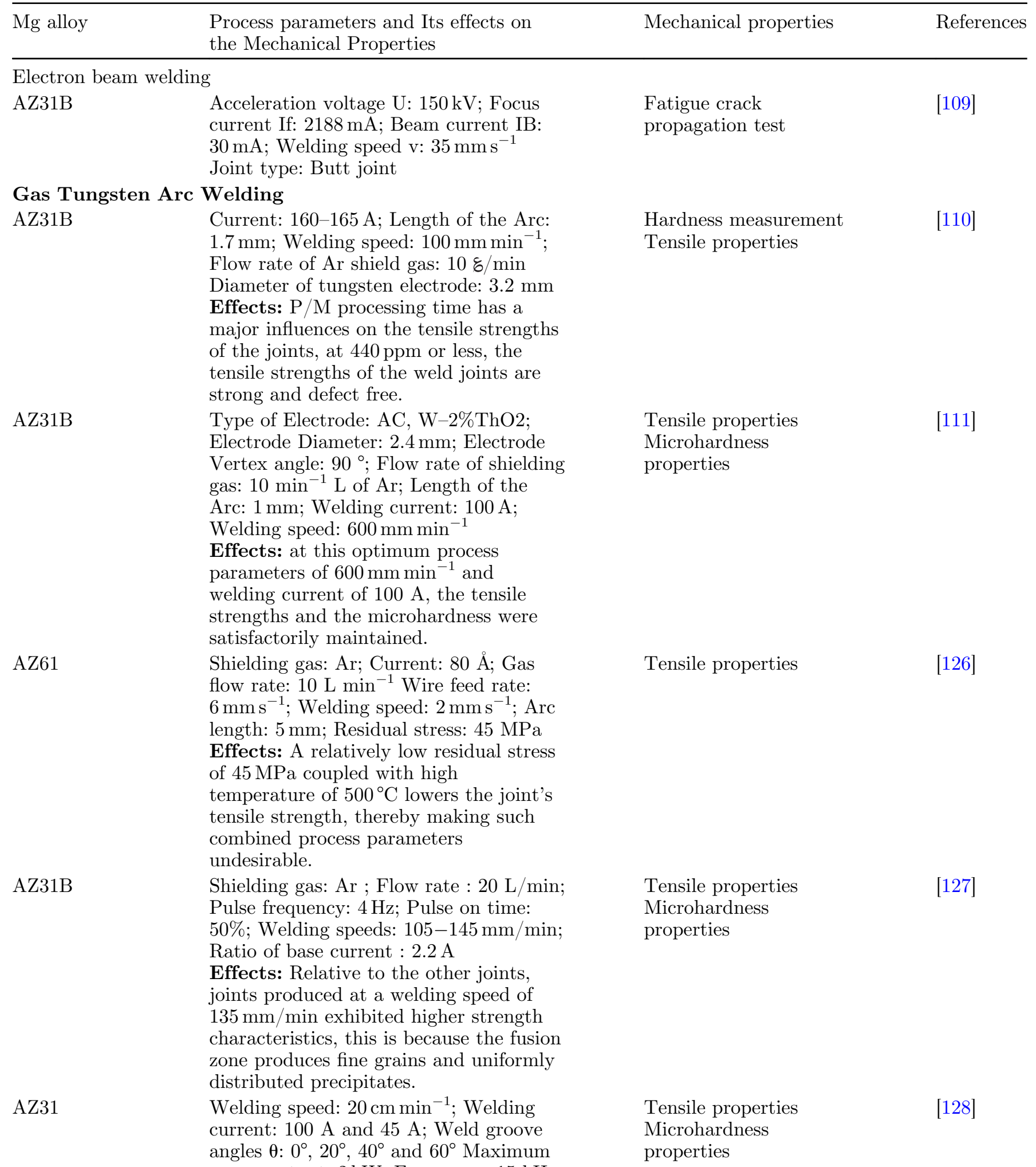


Table 6. (continued).

\begin{tabular}{llll}
\hline $\mathrm{Mg}$ alloy & $\begin{array}{l}\text { Process parameters and Its effects on } \\
\text { the Mechanical Properties }\end{array}$ & Mechanical properties & References \\
\hline
\end{tabular}

zone with the optimal process

parameters of $2 \mathrm{~kW}$ power output and $15 \mathrm{kHz}$ frequency.

LA141

(Mg-Li-Al)

$\mathrm{AZ31} \mathrm{Mg}$

MB3/AZ31

dissimilar

alloy

\section{Laser welding}

ZE41A

AZ31
Welding current: $60 \mathrm{~A}$; Welding speed: 2.8-3.2 $\mathrm{mmin}^{-1}$; Gas flow: 10L/min; Tungsten electrode; Diameter: $2 \mathrm{~mm}$ Effects: The joints performed consistently and quite well, notably in particular, tensile strength and microhardness, when the process parameters of welding current $(60 \mathrm{~A})$ and welding speed range of $2.8-3.2 \mathrm{mmin}^{-1}$ were utilized.

Welding voltage: $80 \mathrm{~A}$; Welding speed: $60 \mathrm{mmin}^{-1}$; Electrode distance: $2 \mathrm{~mm}$; Flow rate of argon gas: $7.51 / \mathrm{min}$ Effects: The process parameters indicated that a large heat input is undesirable since it has a negative impact on the mechanical characteristics of welded joints. However, at the optimum parameters listed above, excellent mechanical properties are achievable.

Welding speed :0.2 $\mathrm{mmin}^{-1}$; Voltage of the arc: $17 \mathrm{~V}$;Shielding gas flow rate: $9 \mathrm{~L}$ min $^{-1}$; Tungsten electrode diameter : $2.5 \mathrm{~mm}$; Ultrasonic power: $1.0 \mathrm{~kW}$;

Welding current : 70 and110 A

Effects: At the optimum process parameters states, the welding defects were eliminated, resulting in increased tensile strength and enhanced microhardness.

Focal length: $150 \mathrm{~mm}$; Fibre diameter: $0.6 \mathrm{~mm}$; Top surface shielding gas: He; Bottom surface shielding gas: Ar; The flow rates were 18.9 and $21.21 \mathrm{~min}^{-1}$; Shielding gad tilting angle: $30^{\circ}$; gap size of the workpieces: 0 to $0.6 \mathrm{~mm}$;

Defocusing range: 0 and $-4 \mathrm{~mm}$; Focal spot diameter: $0.45 \mathrm{~mm}$; Delivering angle of $60^{\circ}$; Power value: 5 and $4 \mathrm{~kW}$; Welding speed from 2 to $7 \mathrm{mmin}^{-1}$

Effects: Weld depth and fusion area reduced as welding speed rose, according to the process conditions. In the case of partly penetrated welding, as welding speed rises, the level of penetration declines.

Laser power: $2 \mathrm{~kW}$; Welding speeds: 50 $\mathrm{mms}^{-1} 100 \mathrm{mms}^{-1}$

Effects: An increased welding speed led to an improved tensile strength coupled
Tensile properties

properties

Tensile properties

Microhardness

properties

Tensile properties

Microhardness

properties

Fresnel absorption

coefficient

Plasma Absorption

Tensile properties 
Table 6. (continued).

\begin{tabular}{llll}
\hline $\mathrm{Mg}$ alloy & $\begin{array}{l}\text { Process parameters and Its effects on } \\
\text { the Mechanical Properties }\end{array}$ & Mechanical properties & References \\
\hline
\end{tabular}

with a lower strain-hardening capacity due to its effect on the refinement of the grain sizes.

Mg-rare earth (NZ30K)

AZ31

AZ31B

AZ31B

AZ31B
Welding speed: $3-5 \mathrm{mms}^{-1}$; Sideblown gas: He; Shielding gas(back): Ar; Spectral data 0.025-nm resolution; Wavelength range: $200-1100 \mathrm{~nm}$; Welding direction: vertical; Frequency: $1000 \mathrm{~s}^{-1}$

Effects: As welding speed increases, plasma temperature falls initially, then rises.

Laser power: $2.75 \mathrm{~kW}$; Welding speed: $33 \mathrm{~m} \mathrm{~min}^{-1}$; Distance: 0.5-2.0 mm; Frequency: $50-200 \mathrm{~Hz}$

Effects: With an increase in the oscillation radius or a drop in the frequency, the breadth of the lap interface rises. At a distance of $2.0 \mathrm{~mm}$ and a frequencyrate of $25 \mathrm{~Hz}$, it reaches $5.75 \mathrm{~mm}$, which is $170 \%$ higher than the weld without beam oscillation.

Welding speed: $2 \mathrm{~m} \mathrm{~min}^{-1}$ maximum power of the laser source :6 kW; Beam quality: $6.9 \mathrm{~mm} / \mathrm{mrad}$; Wavelength: $1070 \mathrm{~nm}$; spot diameter: $0.35 \mathrm{~mm}$; Focal lengths: $150 \mathrm{~mm}$ and $350 \mathrm{~mm}$; Top Shield Gas: Ar with flow rate of $20 \mathrm{~L} /$ min; Root Shield Gas: Ar with flow rate of $8 \mathrm{~L} / \mathrm{min}$

Effects: Low frequency, in combination with the optimal parameters of $2 \mathrm{~kW}$ laser power, $2 \mathrm{~m} / \mathrm{min}$ welding speed, and $0.35 \mathrm{~mm}$ beam oscillating diameter, resulted in increased tensile strength and elongation ratio.

Current: 25 A; Voltage: $30 \mathrm{~V}$; Distance off: $1.3 \mathrm{~mm}$; Electrode diameter: $1.6 \mathrm{~mm}$; Speed: $30 \mathrm{mms}^{-1}$

Effects: The optimum parameters above led to a defect free welded joints thereby enhancing The tensile-shear properties.

Beam power: $1400 \mathrm{~W}$; Focus optics focal range: $192 \mathrm{~mm}$; Placement of the focal point: $0 \mathrm{~mm}$; Beam focal point diameter: $0.2 \mathrm{~mm}$; Welding speed: $1.0 \mathrm{~m} \mathrm{~min}^{-1}$; Anterior protecting gas flow rate: 15 $\mathrm{Lmin}^{-1}$; Posterior protecting gas flow rate: $5 \mathrm{Lmin}^{-1}$

Effects: As a result of carefully selected process parameters, The porosity of the weld drops considerably to less than $1 \%$,
Influence of plasma temperature

Tensile properties

Tensile properties and

Plastic deformation mechanism

Tensile-shear properties

Tensile Properties 
Table 6. (continued).

\begin{tabular}{llll}
\hline Mg alloy & $\begin{array}{l}\text { Process parameters and Its effects on } \\
\text { the Mechanical Properties }\end{array}$ & Mechanical properties & References \\
\hline
\end{tabular}

also, grain refinement also increased

which ultimately enhanced the

mechanical properties considered.

AZ31 and

AZ61

Focus diameter: $0.25 \mathrm{~mm}$; Focal length:

$-1 \mathrm{~mm}$; Laser power: $1.0 \mathrm{~kW}$; Scanning

velocity: $6 \mathrm{~m} / \mathrm{min}$; Upper Shielding gas:

He at $10-20$ Lmin $^{-1}$; Lower Shielding gas: Ar at $5-15 \mathrm{Lmin}^{-1}$

AZ61 Laser power: $1.0 \mathrm{~kW}$; Wavelength:

$1.064 \mathrm{~mm}$; Focal length: $120 \mathrm{~mm}$; Focus

diameter: $0.5 \mathrm{~mm}$; Laser beam power:

350W; Pulse frequency: $35 \mathrm{~Hz}$; Defocus

distance: $1.0 \mathrm{~mm}$; Flow rate: $10 \mathrm{~L} \mathrm{~min}^{-1}$

Ar shielding gas.

AZ31 Laser powers: $1.2-2.0 \mathrm{~kW}$; Welding speed: $60 \mathrm{mms}^{-1}$; Shielding gas: Ar with the Flow rate of $15 \mathrm{Lmin}^{-1}$; Focused laser beam: $400 \mu \mathrm{m}$, Focal length:

$200 \mathrm{~mm}$.

Effects: With a $1.5 \mathrm{~kW}$ welding power, The welded magnesium alloy joints' average microhardness rose to 67.1

HV0.1. During testing, the highest shear force was recorded as a received magnesium alloy welded joint (used laser power of $2.0 \mathrm{~kW}$ ).

$\operatorname{MgAl3Zn1}$

(AZ31)

AlMg3

(AA5754)

AZ61

AZ31B
Laser power: $2.0 \mathrm{~kW}$; Welding speed:

$1.75 \mathrm{~m} \mathrm{~min}^{-1}$; Feed rate: $2.5 \mathrm{~m} \mathrm{~min}^{-1}$;

Diameter $1.6 \mathrm{~mm}$

Effects: Excellent joints were achieved at $1.75 \mathrm{~m} \mathrm{~min}^{-1} 1$ welding speeds.

Spot diameter : $0.2 \mathrm{~mm}$; Beam power:

$1 \mathrm{~kW}$; Welding speed $1800 \mathrm{~mm} \mathrm{~min}^{-1}$ to

$2800 \mathrm{~mm} \mathrm{~min}^{-1}$, Beam Focus

point:1 mm; Flux of shielding

argon10 $\mathrm{Lmin}^{-1}$

Effects: The yield strength, UTS and deformation length of the welded joint were improved once the welding speed was raised from $1800 \mathrm{~mm} \min 1$ to $2800 \mathrm{~m} / \mathrm{min}$. Furthermore, when welding speed rose significantly, the intermediate hardness value in the fusion zone and heat-affected zone (HAZ) increased.

Protective gas: argon Flow rate :12 L $\mathrm{min}^{-1}$; Focal lens: $150 \mathrm{~mm}$; Spot size: $0.3 \mathrm{~mm}$; Wavelength: $1.064 \mathrm{~mm}$; Pulse duration: $3.2 \mathrm{~ms}$; Repetition rate: $40 \mathrm{~Hz}$; Pulse energy: 7.5-12.5 J; Average power P: $0.3-0.5 \mathrm{~kW}$; Focal position: $20.5 \mathrm{~mm}$; Welding speed: $400-800 \mathrm{~mm} / \mathrm{min}$ Effects: Due to trapped oxides in the weld metal when flux was employed, the ultimate tensile strength of the welded
Tensile Properties

Hardness properties

Tensile shear properties

Maximum shear force

Microhardness

properties

Tensile shear properties

Tensile properties

Mechanical properties

Tensile properties 
Table 6. (continued).

\begin{tabular}{lll}
\hline Mg alloy & Process parameters and Its effects on & Mechanical properties \\
& the Mechanical Properties & \\
& joint with activating flux was & \\
& substantially lower than that of the & \\
& welded junction without flux. & Tensile properties \\
& Laser power: $16 \mathrm{~kW}$; Optical fibre & \\
diameter: $200 \mathrm{~mm}$; Focal length: & \\
AZ61A & E0mm; Shielding gas: Ar at 30 Lmin ${ }^{-1}$ & \\
& in the fusion zone, lower values of & \\
& mechanical characteristics were attained & \\
& with increased power input, humping & \\
& was seen at a welding speed of & \\
& 15 min ${ }^{-1}$. Sound welded connections & \\
& may be obtained by stabilizing the & \\
& keyhole with an improved integration of & \\
& process variables. & \\
& Wavelength: $1.064 \mu$ m; maximum peak & Tensile properties
\end{tabular}
power: $10 \mathrm{~kW}$; Pulse duration: $15 \mathrm{~ms}$; Pulse frequency: $30 \mathrm{~Hz}$; Focus radius: $0.25 \mathrm{~mm}$; The peak power $(\mathrm{P}): 0.2$ to $3 \mathrm{~kW}$; Pulse time: $2-14 \mathrm{~ms}$ Effects: With increasing peak power intensity and pulse duration, keyhole welding penetration and aspect ratio rise considerably, whereas the diameter of it mainly rises with pulse time also, the weld diameter is mostly affected by the pulse time in conduction welding, whereas welding penetration is largely unaffected.

AZ31 Power: $0.8-2.0 \mathrm{~kW}$; Pulse time: 4ms; Diameter: 17-1175 $\mu \mathrm{m}$; Penetration: 178$1074 \mu \mathrm{m}$; Aspect ratio: 0.194-0.91 Effects: It was observed that the first crack development orientation is connected to the alteration of the solidification parameters. The solidification fracture is reduced at $10 \mathrm{~ms}^{-0.3} \mathrm{P}$ pulse time.

\section{Metal Inert Gas Welding}

AZ91D

Welding current: 170 A; Welding voltage: $24 \mathrm{~V}$; Welding speeds: $300 \mathrm{~mm} \mathrm{~min}^{-1}$ and $450 \mathrm{~mm} \mathrm{~min}^{-1}$ Effects: Low welding speed $\left(300 \mathrm{~mm} \mathrm{~min}^{-1}\right)$ is undesirable since it resulted in higher heat input, and increased heat input results in degraded tensile characteristics of magnesium alloy welded joints.

AZ31B Diameter: $1.6 \mathrm{~mm}$; Shielding gas: Ar $15 \mathrm{~L} /$ min; Work distance: $15 \mathrm{~mm}$; Welding voltage: $26.5 \mathrm{~V}$; Wire feeding rate: $110-120$ $\mathrm{mm} \cdot \mathrm{s}^{-1}$; Travel Speed: $6.7-10 \mathrm{mms}^{-1}$ Effects: Pores at the joints may be regulated with the right welding process parameters. For illustration, by combining the appropriate travel speed with the wire

Microstructures and cracking characteristics of the welded joints

Tensile properties 
Table 6. (continued).

\begin{tabular}{llll}
\hline $\mathrm{Mg}$ alloy & $\begin{array}{l}\text { Process parameters and Its effects on } \\
\text { the Mechanical Properties }\end{array}$ & Mechanical properties & References \\
\hline
\end{tabular}

feeding speed, the number of pores in the weld may be regulated, and the absence or reduction of pores leads to better tensile and microhardness characteristics.

AZ31 \&

AZ61

AZ31B

AZ31B

AZ61

AZ31B

Ultrasonic welding

AZ31

Power level, vibration frequency and

\section{Laser-TIG hybrid welding}

AZ61

Welding speed: $2000-6000 \mathrm{~mm} \mathrm{~min}^{-1}$. Wavelength: $1.064 \mathrm{~mm}$; Focal length: $120 \mathrm{~mm}$; Spot diameter: $0.4 \mathrm{~mm}$;

Shielding gas: Ar $16 \mathrm{~L} / \mathrm{min}$ feed rate

Effects: The energy input was carefully regulated to ensure that the weld joints' quality.

Welding speed: $800 \mathrm{~mm} \mathrm{~min}^{-1}$; Wire feed rate: $7.0 \mathrm{~m} \mathrm{~min}^{-1}$;

Current (Rework) :170 A; Current

(Pulse) :300A; Frequency(Pulse): $65 \mathrm{~Hz}$; Voltage (Pulse) : 24.9 V; Voltage

(rework) : $24.7 \mathrm{~V}$; Pulse duration: $3.0 \mathrm{~ms}$;

Flow rate: $15 \mathrm{~L} \mathrm{~min}^{-1}$

Effects: the optimum parameters above led to a defect free welded joints thereby enhancing the tensile properties.

Current(base): 50 A; Current (Rework): 140-170 A; Current (Pulse): 290-310 A; Wire feeding rate: $6.5-8.0 \mathrm{~m} \mathrm{~min}^{-1}$; Welding speed: $700-1200 \mathrm{~mm} \mathrm{~min}^{-1}$; Frequency (pulse): 65-75 Hz; Shiled gas flow: $13-16 \mathrm{~L} \mathrm{~min}^{-1}$

Effects: The optimum parameters above led to a defect free welded joints Welding voltage: $23 \mathrm{~V}$; Wire feed rate: $9 \mathrm{~m} \mathrm{~min}^{-1}$; Air flow rate: $17 \mathrm{~L} / \mathrm{min}$; Travel speed: $600 \mathrm{~mm} \mathrm{~min}^{-1}$

Effects: The stated optimal settings resulted in defect-free joints, which reduced spatter loss coefficient feed speed: $5.0-16.0 \mathrm{~m} / \mathrm{min}$; Average current: 90-270 A; Average voltage: 21-27 V; Base current: 25-250 A; Base voltage: $18-25 \mathrm{~V}$; Pulse current:150-600 A; Pulse voltage Up: $28-32 \mathrm{~V}$; Pulse duration: $1.0-6.0 \mathrm{~ms}$; Pulse frequency: $60-90 \mathrm{~Hz}$; Gas flow rate: $13-16 \mathrm{~L} \cdot \mathrm{min}^{-1}$ Effects: The stated optimal settings resulted in defect-free joints, which enhanced the tensile properties of the welded joints. welding time

Tensile properties

Fatigue strength thereby enhancing the tensile properties.

Welding Speed: $600-1000 \mathrm{~mm} / \mathrm{min}$; Wire

Tensile properties

Micro hardness

Tensile Properties

Spatter loss coefficient

Tensile properties

Tensile properties

Tensile strength Microhardness 
Table 6. (continued).

\begin{tabular}{|c|c|c|c|}
\hline Mg alloy & $\begin{array}{l}\text { Process parameters and Its effects on } \\
\text { the Mechanical Properties }\end{array}$ & Mechanical properties & References \\
\hline & $\begin{array}{l}\text { Diameter of the electrode: } 3.2 \mathrm{~mm} \text {; Angle } \\
\text { between electrode and laser beam: } 45^{0} \\
\text { Effects: Welding speed increases } \\
\text { microhardness in the weldment. }\end{array}$ & & \\
\hline \multicolumn{4}{|c|}{ Laser-GTAW hybrid welding } \\
\hline \multicolumn{4}{|c|}{ Laser- TIG hybrid welding } \\
\hline AZ91 & $\begin{array}{l}\text { Electrode angle } \theta: 45^{0} \text {; Electrode } \\
\text { diameter: } 3.2 \mathrm{~mm} \text {; Laser head assembly } \\
\text { to workpiece: } 28 \mathrm{~mm} \text {; Centre of molten } \\
\text { pool to laser spot: } 1.2 \mathrm{~mm} \text {; Defocus } \\
\text { distance D: } 20.8 \mathrm{~mm} \text {; TIG; Current: } 105 \\
\text { A; Welding speed V: } 1500 \mathrm{mmin}{ }^{-1} \text {; Lens } \\
\text { focal length of laser F: } 120 \mathrm{~mm}\end{array}$ & $\begin{array}{l}\text { Immersion test and salt } \\
\text { spray corrosion test }\end{array}$ & [148] \\
\hline
\end{tabular}

causing an increase in the tensile strength and hardness. The effect of input parameters on weld joint of FSWed of AZ91-C Mg alloy is shown in Table 7.

Mechanical properties and welds were enhanced with increasing welding speed in the FSWed joints of Al-Zn$\mathrm{Mg}$ alloy [176]. The effect of the welding speed is shown in the improved strain hardening coefficient and the grain sizes in the SZ. Thus, with increased heat input and rotational speed, and decreased welding speed, the grain sizes are optimized to improve the mechanical properties and weld integrity. By defining and optimizing the input parameters, structural integrity of the weld joints and the mechanical properties can be improved. The effect of low rotation speed on improved fatigue life of AZ31 Mg FSW joints has been studied [154].

The main process varaiables such as rotation and welding speeds have serious effect on mechanical properties through grain size refinement. This has been shown for $\mathrm{Mg}-\mathrm{Zn}-\mathrm{Zr}$ alloy at for $\mathrm{Mg}-\mathrm{Zn}-\mathrm{Zr}$ alloy, a rotational speed of $600 \mathrm{rpm}$ and traveling speed of $300-400 \mathrm{~mm} \mathrm{~min}^{-1}$, results in substantially polished grains [167]. Similar results was also observed in the FSW of AZ31B-H24 Mg alloy with decreasing speed of $20 \mathrm{~mm} / \mathrm{min}$ and increasing rotational rate to $\sim 1000 \mathrm{rpm}$ [176]. Thus, for effective and great weld integrity and mechanical properties close to that of the BM, welding and rotation speeds need to be optimized [157,177-181].
By means of simulated spot solder of magnesium alloy sheets, the effects of increasing absorbed beam strength, processing speed and depth of penetration were shown. For welding currents above $8000 \mathrm{~A}$ with a long slope welding current and high electrode power, blow-free pitch welding with a large nugget and high tensile shear strength was achieved [182]. Generally, increased rotation speed and welding current is necessary to get the best of friction spot welding of $\mathrm{Mg}$ alloys. Table 8 shows a summary of some of the research work that was carried out on solid state welding of $\mathrm{Mg}$ alloys. For fusion welding process (Tab. 6), AZ31 and AZ61 alloys are the most investigated due to their medium strength, good weldability, and formability at ambient temperatures.

\section{Summary of the mechanical properties of fusion and solid-state welding types}

The mechanical properties, primarily tensile and hardness, obtained from fusion welding were compared with those obtained from solid state on a zone-by-zone basis Table 9 and 10, and it was discovered that in both forms of welding, there was a depreciation in the degree of the respective properties as contrasted to the base metal 
Table 7. Weld joint status at different process parameters [172].

\begin{tabular}{lll}
\hline Rotational speed $(\mathrm{r} / \mathrm{min})$ & Traverse speed $(\mathrm{mm} / \mathrm{min})$ & Observation \\
\hline 900 & 80 & Deep groove due to inadequate heat \\
1200 & 80 & Linear fracture due to the inadequate heat \\
1200 & 40 & Slight fracture due to inadequate heat \\
1400 & 40 & Quality weld \\
1400 & 60 & Extensive flush fracture \\
1600 & 20 & Extreme heat, flush and low quality weld \\
\hline
\end{tabular}

mechanical properties. Overall, the fusion zone is effective in enhancing the mechanical properties of the different zones.

\section{Areas for future research direction}

There are some areas of concern and recommendation for the weldability of Mg-based alloys. Magnesium and its alloys have poor room (ambient) temperature ductility due to the basal slips in typical HCP crystals. Prior to welding, there is the need for heating of the Mg-based component, which is easier under laboratory scale experiment. This is expected to induce coarsening mechanism during the heating process. Scalability of this process requires investigation considering there is projected increase usage of Mg-based alloys. Thus, the application of localised heating mechanism and low time cycle can be achieved to improve the mechanical properties. There is also the need to design and develop specific tools and equipment to optimize the right temperature and processing parameters required within an acceptable time frame.

Improving the structural integrity of joints of Mg-based alloys also offer opportunities for further research. Weld joints of Mg-based alloys have volume defects such as porosity, low toughness and susceptibility to cracking. There is the need to design and tailor post weld heat treatment to improve upon the mechanical properties and structural integrity. These must be balanced with cost and explored further for insight.

Magnesium-based alloys with addition of rare earth metals open opportunities for advanced cardiovascular stent materials. Combination of finite element modelling and experimental analyses of the welding activities of these alloy and optimising the process parameters are critical. The use of the two techniques concurrently will reduce the iterative nature of experiments, thus reducing overall cost and providing relative database for optimising composition and mechanical properties. Evaluation of functional and structural properties of weld joints of Mg-based alloys require further studies.

\section{Summary and outlook}

An overview of welding techniques, process variables and their effects on weld performance of Mg-alloys is presented. The naming convention and different types of Mg-based alloys and the effects of alloying elements were briefly discussed. By analysing recent procedures, essential parameters and the weld performance using various techniques, the following conclusions can be made.

The most effective fusion welding technique which improves mechanical properties and aesthetic qualities of the weld joint of $\mathrm{Mg}$ alloys is laser welding. In the case of solid-state welding, friction stir welding showed enhanced mechanical properties with optimized input variables such as rotational and welding speed, which affects the heat input. There is increasing interest on solid-state welding techniques in the past 10 years compared to fusion welding. This is due to less weld defects associated and low heat input of the former. There are new technologies such as laser, coil as well as ultrasonics to augment, complement and strengthen conventional welding processes of Mg-based alloys.

Weld quality and improved mechanical properties depends on the configuration of processing variables. Notable ones include welding speed, welding current, rotational speed, and dwell time. These are critical factors resulting in the tunability of mechanical properties of the weld, fusion and heat affected zones. Optimized process parameters can lead to very fine microstructures $(\sim 2 \mu \mathrm{m}$ grain sizes) from dynamic recrystallization at the weld interface. This results in the Hall-Petch effects with appreciable increase in yield strength, UTS and hardness to about $98 \%$ of the base Mg-alloy. Insufficient input energy generally leads to weld defects such as cracks and voids. Ways should be explored to develop more standard specifications for process parameters to guide the welding and testing of Mg-alloys for structural integrity. This can be done by developing modelling and simulation tools to reduce the Edisonian approach to welding metallurgy, which is costly and time consuming. For instance, temperature variation across the weld joint, as well as grain nucleation and growth can be estimated using simulation or finite element models. These models can produce results consistent with experiments to show how heat, temperature and strain fields are influenced by process parameters.

The constraints of restricted process configurations and the high energy required to join the $\mathrm{Mg}$ alloys continue to be a major challenge. Extensive research through experiments and simulations is still needed to address these challenges. This would be extremely important to ensure that Mg-alloys are deployed in various industries due to good properties they possess. Currently, AZ 31 and AZ63 are the common $\mathrm{Mg}$ alloys due to their great mechanical 
Table 8. Solid state welding process with parameters.

\begin{tabular}{lll}
\hline $\mathrm{Mg}$ Alloy $\quad$ Parameters & $\begin{array}{l}\text { Mechanical properties References } \\
\text { examined }\end{array}$ \\
\hline
\end{tabular}

Friction Stir Welding

AZ3 Rotation rate: $1500 \mathrm{rpm} \& 750 \mathrm{rpm}$; Travel speed: $47.5 \mathrm{~mm} / \mathrm{min}$; Cylindrical stir tool: W18Cr4V; Flat

Fatigue testing shoulder (stir tool): $14 \mathrm{~mm}$; Pin: $4 \mathrm{~mm}$ in diameter, length: $3.8 \mathrm{~mm}$; The welding orientation was perpendicular to the rolling direction.

Effects: The fatigue life of the joint improved as the rotation rate was reduced from $1500 \mathrm{rpm}$ to $750 \mathrm{rpm}$

AZ91 Tool rotational: $800 \mathrm{rpm}$; Traverse speeds: $50 \mathrm{~mm} /$ min; Hexagonal pin tool; Distance between the shoulders (pin length): $0.1 \mathrm{~mm}$ lower than the sheet thickness; Pin length is $7.9 \mathrm{~mm}$.

Effects: The stated optimal settings resulted in an enhanced quality joint, which resulted into an enhanced tensile property of about $121 \mathrm{MPa}$ and $6.9 \%$ elongation.

ZK60 Type of weld: Butt welds; Traveling speeds: from 300 to $400 \mathrm{~mm} / \mathrm{min}$; Rotational speed: $600 \mathrm{rpm}$; Taper angle: $4^{\circ}$

Effects: The findings showed that the plates were effectively welded at the stated processing conditions, with no welding defects occurring. Furthermore, it was observed that the UTS of the joint was $80.3-84.4 \%$ better than that of the parent metal, ZK60

AZ61A Welding speed: $75 \mathrm{~mm} \mathrm{~min}^{-1}$; Force (Axial): $3 \mathrm{kN}$; Tool distance:18 mm; Rotational Speed: $1000 \mathrm{rpm}$; $\mathrm{P}$ in distance: $6 \mathrm{~mm}$; The length of the pin: $5 \mathrm{~mm}$; Profile pinning: Left hand thread of $1 \mathrm{~mm}$ pitch Effects: It was discovered that when the $\mathrm{pH}$ rises, the corrosion rate actually decreases, and the mechanical properties of the joints are influenced by the reduction in corrosion rate.

AZ91 Rotational speed; 710-1400 rpm, Pin diameter: $5 \mathrm{~mm}$ Pin height: $4.8 \mathrm{~mm}$; Shoulder distance: $18 \mathrm{~mm}$; Tilt orientation: $3^{\circ}$

Effects: As the rotation and traverse speeds rise from 710-1400 rpm and 25-100 $\mathrm{mm} \mathrm{min}^{-1}$, the grain size increases, which is unfavourable for the properties being evaluated as they degrade.

AZ91-C Rotational speed: $1400 \mathrm{rpm}$; Horizontal speed; 25$100 \mathrm{~mm} \mathrm{~min}^{-1}$; Shoulder distance: $18 \mathrm{~mm}$; Ultrasonic vibration amplitude :15 um; Welding Speed: $40 \mathrm{~mm}$ $\min ^{-1}$

Effects: The process parameters described resulted in the production of high-quality joints that were defectfree. The microhardness increased from 79 to 87 and the tensile strength improved from 195 to $225 \mathrm{MPa}$.

AZ31 Rotational speed: 1723 revmin $^{-1}$, Travel speed: 32 to

AZ80 $88 \mathrm{~m} \mathrm{~min}^{-1}$, Diameter shoulder of the tool: $10 \mathrm{~mm}$; Pin diameter: $4 \mathrm{~mm}$; Pin length: $2.2 \mathrm{~mm}$

Effects: Fast travel speeds approaching $88 \mathrm{~m} \mathrm{~min}^{-1}$ or slow rotation speeds less than 1723 revmin $^{-1}$ are undesirable because the temperatures are insufficiently high when these welding parameters are utilized, decreasing the quality of welded joints.
Tensile properties;

Temperature, strain, and stress fields

Hardness tests

Tensile tests

Response Surface Methodology (RSM) was used for the Salt Spray Corrosion Test and the Galvanic Corrosion Test.

Dislocation density; Temperature history and strain distribution

Hardness tests Tensile tests

Heat input measurements; influence of melting on heat generation 
Table 8. (continued).

\begin{tabular}{llll}
\hline Mg Alloy & Parameters & $\begin{array}{l}\text { Mechanical properties } \\
\text { examined }\end{array}$ & References \\
\hline AZ31 & Rotational speed: $1000-2000 \mathrm{rpm}$, Plunge depth (PD): & $\begin{array}{l}\text { Thermal cycle } \\
\text { analysis }\end{array}$ & {$[185]$} \\
& $\begin{array}{l}\text { Retracting time: } 2 \mathrm{~s} ; \text { Plunging and Retracting speeds } \\
\text { of the tool: } 1.12-2.5 \mathrm{~mm} / \mathrm{s} \text {; Transverse speed: } 2 \mathrm{~mm} /\end{array}$ & $\begin{array}{l}\text { Overlap joint lap } \\
\text { shear testing }\end{array}$ &
\end{tabular}
$\min$.

Effects: Optimal settings led to enhanced quality joint, improving thermal and mechanical properties of the overlap joints. In comparison to the BM, the growth correlation between the sheet length and top width increased to $13.9 \%$.

AZ31B Tool tilt: $3^{0}$; Rotation speed: 200-300 rpm; Rotation direction: CCW; Travel speed: $500 \mathrm{~mm} / \mathrm{min}$ Effects: The concave-DFSW stir zone's mean grain size increases as the bottom tool's rotation rate lowers rom 300 to $200 \mathrm{rpm}$. As a result, the joints' tensile properties improved.

AZ31 Pin Length: $1.65 \mathrm{~mm}$; Pin diameter: $3.175 \mathrm{~mm}$; Welding speed: $5-20 \mathrm{mms}^{-1}$; Tool Rotational Rates: 1000-2000 rpm

Effects: Quality joints with yield strength of 285 Mpa in contrast to the base metal's $265 \mathrm{MPa}$ were produced.

AZ31-O Pin diameter: $5 \mathrm{~mm}$; Tool rotation rate: $1000 \mathrm{rpm}$; Welding speed: $200 \mathrm{~mm} \mathrm{~min}^{-1}$; Shoulder distance: $10 \mathrm{~mm}-13 \mathrm{~mm}$

Effects: The tensile properties of the welded samples were lower than those of the AZ31 BM

AZ61A Rotational speed: 1000rpm; Force(axial): $3 \mathrm{kN}$; Shoulder distance:18mm; Pin diameter: $6 \mathrm{~mm}$; Pin length: $5 \mathrm{~mm}$

Effects: The stated optimum process parameters resulted in an enhanced quality joint, which in turn resulted in a lower corrosion rate, affecting the joints' longevity.

Al-Zn-Mg Tool shoulder :20 mm, Cylindrical threaded pin:8mm; Tool rotational rate: $800 \mathrm{rmin}^{-1}$, Welding speed :100 to $400 \mathrm{~m} \mathrm{~min}^{-1}$.

Effects: At optimum parameters of $400 \mathrm{~m} \mathrm{~min}^{-1}$ welding speed, and a rotational rate of $800 \mathrm{rmin}^{-1}$, Excellent joints were obtained of $91 \%$ compared to the base metal were achieved

AZ31 Shoulder Diameter: $12 \mathrm{~mm}$; Pin diameter: $3.5 \mathrm{~mm}$; Pin height: $7 \mathrm{~mm}$; Pin angle: $30^{\circ}$; Rotational speed: 1200 , 1500 and $2500 \mathrm{rpm}$; Welding speed: $30-100 \mathrm{~mm} \mathrm{~min}^{-1}$, Effects: The vertical force value increases when the welding speed falls from 1500 to $1200 \mathrm{rpm}$ and the rotating speed reduces from 100 to 60 , then to 30 , forces and temperatures have been linked to joint mechanical characteristics

AZ31B Rotational Speed: 1500-1800 rpm; Traverse Speed: $100-120 \mathrm{~mm} \mathrm{~min}^{-1}$; different pin profiles: Cylindrical and truncated conical

Effects: Excellent joints were achieved using the abovementioned parameters, including a controlled welding speed of $100 \mathrm{~mm} \mathrm{~min}^{-1}$ and an optimum rotational speed of $1500 \mathrm{rpm}$, which resulted in defect-free joints.
Tensile tests

[186]

Microhardness tests

Tensile tests

Tensile tests

Residual stress

distribution

[188]

Immersion Corrosion in $\mathrm{NaCl}$ solution

[189]

Joint efficiency;

Hardening capacity yield strength, ultimate tensile strength, ductility, net low stress

Tensile test

Temperature test

Defect formation analysis
[191] 
Table 8. (continued).

\begin{tabular}{|c|c|c|c|}
\hline Mg Alloy & Parameters & $\begin{array}{l}\text { Mechanical properties } \\
\text { examined }\end{array}$ & References \\
\hline AZ31 & $\begin{array}{l}\text { Rotational speed: } 1500-1600 \mathrm{rpm} \text {; Weld speed: } 100 \\
-120 \mathrm{~min}^{-1} \text {; Plunge Depth: } 0.3-0.4 \mathrm{~mm} \\
\text { Effects: Excellent joints with improved } \\
\text { microhardness of } 84 \mathrm{HV} \text { ( } 16 \text { percent enhancement) } \\
\text { were achieved in the weld nuggets at optimal settings } \\
\text { of } 1500 \mathrm{rpm} \text { (rotational speed) and } 100 \mathrm{~mm} \mathrm{~min}^{-1} \\
\text { (welding speed). }\end{array}$ & Micro hardness & {$[161]$} \\
\hline AZ31 & $\begin{array}{l}\text { Welding traverse speed } ; 15 \mathrm{mms}^{-1} \\
\text { Rotation speed of } 1000 \mathrm{rpm}\end{array}$ & $\begin{array}{l}\text { Average temperate } \\
\text { and viscosity }\end{array}$ & [192] \\
\hline
\end{tabular}

Effects: Excellent joints with improved average and viscosity temperature and viscosity were produced at the optimal values indicated above.

AZ80 Advance per Rotation: 0.107-0.425 mm

Welding speed: $88-248 \mathrm{~m} \mathrm{~min}^{-1}$

Rotational Speed: 583-820 RPM

Effects: Excellent joints evidenced with microstructural analysis clear were produced at the optimal values of increased RPM indicated above.

AZ91-D Welding speed: $90 \mathrm{~mm} / \mathrm{min}$; Tool rotation rate $\mathrm{W}: 120$ RPM; Welding Pression: $1200 \mathrm{kN}$

Effects: Excellent joints were produced at the optimal values indicated above and the effects were seen in the superior tensile properties it displayed. Furthermore, Experiments indicated that raising the welding speed $(\mathrm{V})$ while maintaining the tool rotation rate $(\mathrm{W})$ constant caused internal holes and a deficiency of bonding process owing to insufficient material flow.

AZ31B Rotational speeds: 700, 900, 1100, 1300 and $1500 \mathrm{rpm}$. Travelling speed: $50 \mathrm{~mm} / \mathrm{min}$; Tool tilt: $2.5^{\circ}$

Effects: The average grain size rises as rotating speed increases. Furthermore, the UTS of the joints vastly improves as the rotational speed increases, with an excellent joint efficiency of $97 \%$.

AZ31 Tool Rotational; Speed: 300-3000 rpm; Weld Pitch: 0.1000-0.6667 mm; Welding Temperature: 0.57 $0.85 \mathrm{Tm}$

Effects: Excellent joints evidenced with clear microstructural analysis were produced at the optimal values indicated above.

AZ31B-H24 Welding direction: perpendicular to the rolling direction of the workpiece; Welding speed: $10 \mathrm{~mm} / \mathrm{s}$ or $20 \mathrm{~mm} / \mathrm{s}$; The tool rotational rates: $1000 \mathrm{rpm}$ and $1500 \mathrm{rpm}$ Pin length: $2.75 \mathrm{~mm}$

Effects: The hook length and consequent fatigue life were severely impacted by process welding conditions. Hooking flaws were removed using the best combination of $1000 \mathrm{rpm}$ and $20 \mathrm{~mm} / \mathrm{s}$ welding speed, which improved the welding and joint fatigue life.

AZ31B Welding speed: $10-20 \mathrm{mms}^{-1}$; Rotational rate: 1000$1500 \mathrm{rpm}$, Pin length: $2.75 \mathrm{~mm}$

Microstructural analysis

Hardness tests

Tensile tests

Microhardness tests;

Tensile tests; Strain, Hardening; Fracture behaviour

Microhardness

Fatigue Properties

Effects: The best joints with the required mechanical characteristics were produced by combining a high welding speed of $20 \mathrm{mms}^{-1}$ with a low tool rotating rate of $1000 \mathrm{rpm}$.

Microhardness

Tensile Shear Properties 
Table 8. (continued).

\begin{tabular}{llll}
\hline Mg Alloy & Parameters & $\begin{array}{l}\text { Mechanical properties } \\
\text { examined }\end{array}$ & References \\
\hline Mg-5Al-3Sn & $\begin{array}{l}\text { Tool tilt angle: } 2.5^{\circ} \text {; Rotation rate: } 1000 \mathrm{rpm} \text {; Welding } \\
\text { speed: } 120,150 \text { and } 180 \mathrm{~mm} \mathrm{~min}^{-1} \text {; Shoulder plunge } \\
\text { depth: } 0.15 \mathrm{~mm}\end{array}$ & $\begin{array}{l}\text { Hardness and Tensile } \\
\text { i tests }\end{array}$ & [196]
\end{tabular}

Effects: The increase in welding speed did not

ZE41 Shoulder diameter: $30 \mathrm{~mm}$ pin Diameter: $17 \mathrm{~mm}$;

Length: $6 \mathrm{~mm}$; Projection: 1-4 mm; Dwell Time: 25-

60 s; Rotational speed: $600-1000 \mathrm{rpm}$

Effects: Excellent joints evidenced with reduction of defects such as interface cracking, wedge cracking and matrix cracking were produced at the optimal values of lower rotational speed (around 600-681 rpm) and higher dwelling time (around 53-60 s).

AZ91D Rotational speed: 1200-1600 rpm; Welding speed: 25$75 \mathrm{~mm} \mathrm{~min}{ }^{-1}$; Force (axial): $2-6 \mathrm{kN}$.

Effects: To achieve good joints with exceptional tensile properties, the best process parameter combinations were determined to be a rotating speed of $1400 \mathrm{rpm}$, a welding speed of $50 \mathrm{~m} \mathrm{~min}^{-1} 1$, and an axial force of $4 \mathrm{kN}$.

AZ91 Welding speed: $1.5 \mathrm{~mm} \mathrm{~min}^{-1}$; Rotation rate:

AZ61 $1400 \mathrm{rpm}$, Wire feed rate: $25 \mathrm{~mm} \mathrm{~min}^{\& \# \mathrm{x} 2212}$ Tool Diameter: $20 \mathrm{~mm}$; Shoulder Distance: $18 \mathrm{~mm}$; Shoulder Length: $18 \mathrm{~mm}$; Pin Profile: Threaded with the left hand, Pin Length: $3.8 \mathrm{~mm}$; Pin Diameter: $6 \mathrm{~mm}$; Tool tilt angle: $0^{\circ}$.

Effects: Excellent joints were obtained at the optimum values of $1400 \mathrm{rpm}$ (rotational speed) and $25 \mathrm{~mm} \min ^{-1}$ (welding speed), as depicted by the rise in the tensile strength $(130.17 \mathrm{MPa})$ and percentage efficiency (59 percent) of the joints when compared to the base alloy (AZ91 magnesium alloy)

\section{Friction Spot Welding}

AZ31 Rotation rate: $1400 \mathrm{rev} \mathrm{min}^{-1}$; Tool plunging rate: $20 \mathrm{~mm} \mathrm{~min}^{-1}$; Plunge depth: $0.3 \mathrm{~mm}$, Dwell time: $10-$ $25 \mathrm{~s}$; Shoulder diameter: $12 \mathrm{~mm}$; Pin diameter: $4 \mathrm{~mm}$; Pin height: $2.8 \mathrm{~mm}$

Effects: Because of the fluctuation in grain size, the microhardness and tensile shear strength rose initially and subsequently dropped as the dwell duration increased. The best dwell time is determined to be 10 to $15 \mathrm{~s}$, allowing for the best mechanical characteristics of the welded joints.

AZ31B Vibration frequency: $19 \mathrm{kHz}$; Pin rotating rate:

6061-T6 $1000 \mathrm{rpm}$; Plunge rate: $5 \mathrm{~mm} \mathrm{~min}^{-1}$; Shoulder plunge depth: $0.3 \mathrm{~mm}$; Retracting speed: $10 \mathrm{~m} \mathrm{~min}^{-1}$ Dwell time: $5 \mathrm{~s}$

Effects: Excellent joints evidenced with satisfactory tensile properties and the required microhardness were produced at the optimal values indicated above

ZEK100 Welding energy: 500-2500 J; Power Setting: $2 \mathrm{KwW}$, Pressure: $0.4 \mathrm{MPa}$.

Tensile tests

Tensile tests

Tensile tests

microhardness

Lap tensile shear

tests

Microhardness

Tensile test hardness

Effects: For welding energy above $1500 \mathrm{~J}$, the welded joints were undesirable with severe plastic

Microhardness deformation 
Table 8. (continued).

\begin{tabular}{|c|c|c|c|}
\hline Mg Alloy & Parameters & $\begin{array}{l}\text { Mechanical properties } \\
\text { examined }\end{array}$ & References \\
\hline AZ31B & $\begin{array}{l}\text { Welding current: } 10 \mathrm{kA} \text {; Electrode force: } 2 \mathrm{kN} \text {; } \\
\text { Welding time: } 10 \text { cycles } \\
\text { Effects: Microstructural analysis at the optimum } \\
\text { values shown above indicates excellent joints. }\end{array}$ & $\begin{array}{l}\text { Microstructural } \\
\text { analysis }\end{array}$ & {$[201]$} \\
\hline AZ31B & $\begin{array}{l}\text { Welding time: } 0.17 \mathrm{~s} \text {; Welding current } 2-12 \mathrm{kA} \text {; } \\
\text { Welding slope time: } 0.83 \mathrm{~s} \text {; Electrode force } 1-3 \mathrm{kN} \text {; } \\
\text { Diameter of electrode tip: } 6 \mathrm{~mm} \\
\text { Effects: When welding currents were over } 8000 \mathrm{~A} \\
\text { and electrode force was raised, defects-free junctions } \\
\text { were obtained. }\end{array}$ & $\begin{array}{l}\text { Tensile shear } \\
\text { strength of the joint }\end{array}$ & {$[182]$} \\
\hline AZ31 & $\begin{array}{l}\text { Rotation speed: } 950,1180 \mathrm{rpm} \text {; Dwell time: } 3-15 \mathrm{~s} \text {; } \\
\text { Depth of the plunge: } 0.3 \mathrm{~mm} \text {; Plunge rate: } 30 \mathrm{~mm} / \mathrm{min} \\
\text { Effects: The depth of the stir zone steadily rises as the } \\
\text { rotation speed and dwell duration increase. The } \\
\text { process parameters are } 1180 \mathrm{rmin}^{-1} \text { rotation speed and } \\
9 \mathrm{~s} \text { well time, which resulted in an excellent } 4.22 \mathrm{kN} \\
\text { maximum tensile shear strength. }\end{array}$ & $\begin{array}{l}\text { Tensile shear } \\
\text { strength } \\
\text { Microhardness }\end{array}$ & [202] \\
\hline
\end{tabular}

Table 9. Mechanical properties of different zones of fusion welded Mg-alloys.

\begin{tabular}{llll}
\hline Mg Alloy & Hardness Property (HV) & Tensile Strength (MPa) & References \\
\hline $\begin{array}{l}\text { Tungsten inert gas (TIG) welding } \\
\text { AZ91D }\end{array}$ & & BM: 160; HAZ: 156; WM: 240 & {$[203]$} \\
MB3/AZ31 dissimilar & BM: 56.8; HAZ:48.1; FZ:52.0 & 263 MPa, & {$[130]$} \\
AZ31 joints & HAZ: 15; FZ:73 & BM:240 & {$[204]$} \\
LA141 Mg-Li-Al & BM: 72; FZ: 66 & BM: 127; FZ: 124 & {$[64]$} \\
AZ31B joints & BM:69; FZ: 61 & BM: 275; FZ: 220 & {$[75]$} \\
AZ31B & BM: 62; FZ: 59 & BM: 275; FZ: 201 & {$[127]$} \\
AZ61 & nil & BM:250; FZ:230 & {$[126]$} \\
AZ31B & BM: 52; FZ: 48 & BM: 259; FZ: 224 & {$[111]$} \\
AZ31B & BM: 65; FZ: 58 & BM: 280; FZ: 258 & {$[205]$} \\
Laser welding & & & {$[95]$} \\
AZ31B-H24 & BM: 73; FZ: 54; HAZ: 51 & BM: 282; FZ: 254 & {$[92]$} \\
AZ31B Mg alloy & Nil & FZ: 232 & {$[134]$} \\
AZ31B & Nil & BM: 302.2; FZ: 274.1 & {$[206]$} \\
AZ31 and AZ61 & BM:62; FZ:72 & BM:308; FZ:153 & {$[207]$} \\
AZ31 & FZ: 67.1 & Nil & {$[138]$} \\
MgAl3Zn1 (AZ31) & Nil & FZ:240 & {$[96]$} \\
AZ61 Mg alloy & BM:58; HAZ:56; FZ:64 & BM:285; FZ:236 & {$[28]$} \\
AZ31B alloy & Nil & BM:258; FZ:235 & {$[89]$} \\
AZ31B and AZ61A & Nil & BM: 298; FZ: 273 &
\end{tabular}


Table 10. Mechanical properties of different zones of solid-state welded Mg-alloys.

\begin{tabular}{llll}
\hline Alloy & Hardness (HV) & Tensile Strength (MPa) & References \\
\hline Friction Stir welding & & & \\
AZ31 & BM:63; HAZ:69; SZ: 62 & BM:285; FZ: 269 & {$[166]$} \\
AZ31B & Nil & BM: 231; SZ: 229 & {$[208]$} \\
AZ91- & SZ: 87 & BM: $121 ;$ HAZ: 128 & {$[172]$} \\
AZ91 & NIl & BM: 583; SZ: 632 & {$[183]$} \\
Al-Zn-Mg & Nil & BM:248 & {$[176]$} \\
AZ31 & BM: 84 & BM: 230; HAZ:200 & {$[161]$} \\
AZ91-D & BM:92; HAZ: 90; TMAZ:80; NZ:85 & BM:76; HAZ:104 & {$[42]$} \\
AZ31B & BM:52; HAZ:56; TMAZ/SZ :44 & Nil & {$[209]$} \\
AZ31B-H24 & BM:75; HAZ:62; SZ:52 & BM:297 & {$[178]$} \\
Mg-5Al-3Sn & BM:72; HAZ:59; NZ:76; TMAZ:73 & & {$[196]$} \\
Friction spot welding & & Nil & {$[200]$} \\
ZEK100 & BM: 61; NZ:57 & BM: 109.6 & {$[210]$} \\
AZ31; AZ61; AZ80 & NIl & &
\end{tabular}

properties and ease of weldability. The design and development of new or improvement of existing welding technique will ensure many of $\mathrm{Mg}$ alloys desired in this review would become beneficial to structural and functional applications.

\section{References}

1. J. Yang, F.Z. Cui, I.S. Lee, X. Wang, Plasma surface modification of magnesium alloy for biomedical application, Surf. Coatings Technol. 205 (2010) S182-S187

2. J. Zhang, Q. Yu, Y. Jiang, Q. Li, An experimental study of cyclic deformation of extruded AZ61A magnesium alloy, Int. J. Plast. 27 (2011) 768-787

3. S. Zhu, T. Luo, T. Zhang, Y. Liu, Y. Yang, Effects of extrusion and heat treatments on microstructure and mechanical properties of $\mathrm{Mg}-8 \mathrm{Zn}-1 \mathrm{Al}-0.5 \mathrm{Cu}-0.5 \mathrm{Mn}$ alloy, Trans. Nonferrous Met. Soc. China 27 (2017) 73-81

4. X. Gu, Y. Zheng, Y. Cheng, S. Zhong, T. Xi, In vitro corrosion and biocompatibility of binary magnesium alloys, Biomaterials 30 (2009) 484-498

5. H. Westengen, 9 Magnesium, Light Met. Age Mag. 58 (2000) 44-52

6. B.L. Mordike, T. Ebert, Magnesium: properties applications - potential, Mater. Sci. Eng. A 302 (2001) $37-45$

7. M. Heger, M. Horstmann, 9-Mechanical joining of magnesium alloys, in Woodhead Publishing Series in Welding and Other Joining Technologies, edited by M.A. Liu (Woodhead Publishing, 2010), pp. 122-148

8. N. Sezer, Z. Evis, S.M. Kayhan, A. Tahmasebifar, M. Koç, Review of magnesium-based biomaterials and their applications, J. Magnes. Alloy. 6 (2018) 23-43

9. N. Sezer, Z. Evis, S.M. Kayhan, A. Tahmasebifar, M. Koç, Review of magnesium-based biomaterials and their applications, J. Magn. Alloy. 6 (2018) 23-43
10. L. Zhang, J. Zhang, C. Chen, Y. Gu, Advances in microarc oxidation coated AZ31 Mg alloys for biomedical applications, Corros. Sci. 91 (2015) 7-28

11. L. Liu, Front matter, in Woodhead Publishing Series in Welding and Other Joining Technologies, edited by M.A. Liu (Woodhead Publishing, 2010), pp. i-iii

12. X. Cao, M. Jahazi, J.P. Immarigeon, W. Wallace, A review of laser welding techniques for magnesium alloys, J. Mater. Process. Technol. 171 (2006) 188-204

13. L. Liu, D.-H. Cai, Z.-D. Zhang, Gas tungsten arc welding of magnesium alloy using activated flux-coated wire, Scr. Mater. - Scr. MATER 57 (2007) 695-698

14. N.J. Kim, Critical Assessment 6: Magnesium sheet alloys: Viable alternatives to steels?, Mater. Sci. Technol. 30 (2014) $1925-1928$

15. T.T.T. Trang, J.H. Zhang, J.H. Kim, A. Zargaran, J.H. Hwang, B.C. Suh, N.J. Kim, Designing a magnesium alloy with high strength and high formability, Nat. Commun. 9 (2018) doi: 10.1038/s41467-018-04981-4

16. S.R. Agnew, Ö. Duygulu, Plastic anisotropy and the role of non-basal slip in magnesium alloy AZ31B, Int. J. Plast. 21 (2005) 1161-1193

17. K. Frydrych, T. Libura, Z. Kowalewski, M. Maj, K. Kowalczyk-Gajewska, On the role of slip, twinning and detwinning in magnesium alloy AZ31B sheet, Mater. Sci. Eng. A 813 (2021) doi: 10.1016/j.msea.2021.141152

18. Z.D. Zhang, Q.J. Cao, Study on metal transfer behaviour in metal inert gas arc welding with activating flux for magnesium alloy, Sci. Technol. Weld. Join. 17 (2012) 550-555

19. M. Iqbal, M. Ayub, Z. Majeed, H.M. Akram, Optimal welding parameters with $10 \mathrm{keV}$ point source electron gun, Vacuum 85 (2011) 654-656

20. Z.D. Zhang, Q.J. Cao, Study on metal transfer behaviour in metal inert gas arc welding with activating flux for magnesium alloy, Sci. Technol. Weld. Join. 17 (2012) 550-555

21. Y.-C. Lin, J.-J. Liu, B.-Y. Lin, C.-M. Lin, H.-L. Tsai, Effects of process parameters on strength of $\mathrm{Mg}$ alloy AZ61 friction stir spot welds, Mater. Des. 35 (2012) 350-357 
22. Y.H. Yin, N. Sun, T.H. North, S.S. Hu, Microstructures and mechanical properties in dissimilar AZ91/AZ31 spot welds, Mater. Charact. 61 (2010) 1018-1028

23. Q. Yang, S. Mironov, Y.S. Sato, K. Okamoto, Material flow during friction stir spot welding. Mater. Sci. Eng. A 527 (2010) 4389-4398

24. K. Abderrazak, W. Ben Salem, H. Mhiri, G. Lepalec, M. Autric, Modelling of $\mathrm{CO}_{2}$ laser welding of magnesium alloys, Opt. Laser Technol. 40 (2008) 581-588

25. M. Gao, H. Wang, K. Hao, H. Mu, X. Zeng, Evolutions in microstructure and mechanical properties of laser lap welded AZ31 magnesium alloy via beam oscillation, J. Manuf. Process. 45 (2019) 92-99

26. M. Gao, H.-G. Tang, X.-F. Chen, X.-Y. Zeng, High power fiber laser arc hybrid welding of AZ31B magnesium alloy, Mater. Des. 42 (2012) 46-54

27. L. Liu, Contributor contact details, in Woodhead Publishing Series in Welding and Other Joining Technologies, edited by M.A. Liu (Woodhead Publishing, 2010), pp. xi-xiii

28. H. Sun, G. Song, L.F. Zhang, Effects of oxide activating flux on laser welding of magnesium alloy, Sci. Technol. Weld. Join. 13 (2008) 305-311

29. H. Shi, R. Qiu, J. Zhu, K. Zhang, H. Yu, G. Ding, Effects of welding parameters on the characteristics of magnesium alloy joint welded by resistance spot welding with cover plates, Mater. Des. 31 (2010) 4853-4857

30. X. Cao, M. Jahazi, Effect of welding speed on the quality of friction stir welded butt joints of a magnesium alloy, Mater. Des. 30 (2009) 2033-2042

31. G. Mahendran, V. Balasubramanian, T. Senthilvelan, Developing diffusion bonding windows for joining AZ31B magnesium-AA2024 aluminium alloys, Mater. Des. 30 (2009) 1240-1244

32. L. Peng, L. Yajiang, G. Haoran, W. Juan, A study of phase constitution near the interface of $\mathrm{Mg} / \mathrm{Al}$ vacuum diffusion bonding, Mater. Lett. 59 (2005) 2001-2005

33. H. Liu, J. Zhou, D. Zhao, Y. Liu, J. Wu, Y. Yang, B. Ma, H. Zhuang, Characteristics of AZ31 Mg alloy joint using automatic TIG welding, Int. J. Miner. Metall. Mater. 24 (2017) 102-108

34. D. Min, J. Shen, S. Lai, J. Chen, N. Xu, H. Liu, Effects of heat input on the low power Nd:YAG pulse laser conduction weldability of magnesium alloy AZ61, Opt. Lasers Eng. 49 (2011) 89-96

35. L. Lihui, L. Kangning, G. Cai, X. Yang, C. Guo, G. Bu, A critical review on special forming processes and associated research for lightweight components based on sheet and tube materials, Manuf. Rev. 1 (2014). doi: 10.1051/mfreview/2014007

36. B. Skowronska, T. Chmielewski, D. Golanski, J. Szulc, Weldability of S700MC steel welded with the hybrid plasma + MAG method, Manuf. Rev. 7 (2020) doi: 10.1051/mfreview/ 2020001

37. T. Wang, P. Upadhyay, S. Whalen, A review of technologies for welding magnesium alloys to steels, Int. J. Precis. Eng. Manuf. Technol. (2020) doi: 10.1007/s40684-020-00247-x

38. U. A, J. Dhas, Friction stir welding of magnesium alloys - a review, Adv. Mater. Sci. Eng. An Int. J. 2 (2015) 7-18

39. P. Asadi, Welding of magnesium alloys, Sci. Am. (2012) 107-119

40. N.S. Mohamed, J. Alias, A review on the effect of welding on the corrosion of magnesium alloys, IOP Conf. Ser. Mater. Sci. Eng. 257 (2017)
41. S. Satonaka, C. Iwamoto, G. Murakami, Y. Matsumoto, Resistance spot welding of magnesium alloy sheets with cover plates, Weld. World 56 (2012) 44-50

42. A. Kouadri-Henni, L. Barrallier, Mechanical properties, microstructure and crystallographic texture of magnesium AZ91-D alloy welded by friction stir welding (FSW), Metall. Mater. Trans. A Phys. Metall. Mater. Sci. 45 (2014) 4983 4996

43. V. Subravel, G. Padmanaban, V. Balasubramanian, Effect of welding speed on microstructural characteristics and tensile properties of GTA welded AZ31B magnesium alloy, Trans. Nonferrous Met. Soc. China 24 (2014) 2776-2784

44. M. Gao, X.Y. Zeng, B. Tan, J.C. Feng, Study of laser MIG hybrid welded AZ31 magnesium alloy, Sci. Technol. Weld. Join. 14 (2009) 274-281

45. K. Hantzsche, J. Bohlen, J. Wendt, K.U. Kainer, S.B. Yi, D. Letzig, Effect of rare earth additions on microstructure and texture development of magnesium alloy sheets, Scr. Mater. 63 (2010) 725-730

46. B.Q. Shi, R.S. Chen, W. Ke, Effects of yttrium and zinc on the texture, microstructure and tensile properties of hotrolled magnesium plates, Mater. Sci. Eng. A 560 (2013) $62-70$

47. W.. Oates, A. Saitta, Welding Handbook (American Welding Society, Miami, 1998)

48. U.S. Dixit, V. Yadav, P.M. Pandey, A. Roy, V.V. Silberschmidt, 14-Modeling of friction in manufacturing processes, in Elsevier Series in Mechanics of Advanced Materials, edited by P.T. Silberschmidt (Elsevier, 2020), pp. 415-444

49. A. Dhanapal, S.R. Boopathy, V. Balasubramanian, K. Chidambaram, A.R.T. Zaman, Experimental investigation of the corrosion behavior of friction stir welded AZ61A magnesium alloy welds under salt spray corrosion test and galvanic corrosion test using response surface methodology, Int. J. Met. (2013) 1-17

50. J. Cornu, Historical devel opmen T of, Fundam. Fusion Weld. Technol. (1988)

51. E. Bayraktar, 6.01-Introduction to Welding and Bonding Technologies, edited by S. Hashmi, G.F. Batalha, C.J. Van Tyne, B.B.T.-C.M.P. Yilbas (Elsevier, Oxford, 2014) pp. $1-2$

52. H. Bhadeshia, R. Honeycombe, Chapter 13-Weld Microstructures, H. Bhadeshia and R.B.T.-S.M. and P. (Fourth E. Honeycombe, Eds. Butterworth-Heinemann, 2017, pp. 377-400. doi: 10.1016/B978-0-08-100270-4.00013-5

53. C. Johansson, 22-Quality assurance and quality management, in Woodhead Publishing Series in Welding and Other Joining Technologies, edited by S.E. Weman (Woodhead Publishing, 2012), pp. 245-258

54. D. Davidson, K. Chan, R. McClung, S. Hudak, Comprehensive Structural Integrity (2003), pp. 129-161

55. F. Czerwinski, Welding and Joining of Magnesium Alloys (2011). doi: 10.5772/13947

56. O.S. Ogbonna, S.A. Akinlabi, N. Madushele, P.M. Mashinini, A.A. Abioye, Application of MIG and TIG welding in automobile industry, J. Phys. Conf. Ser. 1378 (2019) doi: 10.1088/1742-6596/1378/4/042065

57. A. Jagetia, M.S.K.K. Nartu, S. Dasari, A. Sharma, B. Gwalani, R. Banerjee, Ordering-mediated local nanoclustering results in unusually large hall-petch strengthening coefficients in high entropy alloys, Mater. Res. Lett. Under Rev. (2020) doi: 10.1080/21663831.2020.1871440 
58. M. Zhao, J.C. Li, Q. Jiang, Hall-Petch relationship in nanometer size range, J. Alloys Compd. 361 (2003) 160-164

59. N. Hansen, Hall-Petch relation and boundary strengthening 51 (2004), 801-806, doi: 10.1016/j.scripta mat.2004.06.002

60. S. Kou, Y. Le, Nucleation mechanisms and grain refining of weld metal, Weld. J. (Miami, Fla) 65 (1986)

61. G. Padmanaban, V. Balasubramanian, Influences of pulsed current parameters on mechanical and metallurgical properties of gas tungsten arc welded AZ31B magnesium alloys, Met. Mater. Int. 17 (2011) 679-687

62. G. Wu, D. Zhao, L. Sun, Microstructure and mechanical properties of wire-filled tungsten argon arc welded joints for LA141 magnesium-lithium-aluminum alloy, Mater. Today Commun. 23 (2020) 100881

63. D.X. Sun, D.Q. Sun, X.Y. Gu, Z.Z. Xuan, Hot cracking of metal inert gas arc welded magnesium alloy AZ91D, ISIJ Int. 49 (2009) 270-274

64. G. Wu, D. Zhao, L. Sun, Microstructure and mechanical properties of wire-filled tungsten argon arc welded joints for LA141 magnesium-lithium-aluminum alloy, Mater. Today Commun. 23 (2020) 100881

65. S.R.K. Rao, G.M. Reddy, M. Kamaraj, K.P. Rao, Grain refinement through arc manipulation techniques in AlCu alloy GTA welds, Mater. Sci. Eng. A 404 (2005) 227-234

66. V. Subravel, N. Alagappan, N. Babu, Influence of arc oscillation frequency on tensile properties and microstructural characteristics of magnetic arc oscillation welded AZ31B magnesium alloy joints, Mater. Today Proc. 22 (2020) 606-613

67. F. Yang, J. Zhou, R. Ding, Ultrasonic vibration assisted tungsten inert gas welding of dissimilar magnesium alloys, J. Mater. Sci. Technol. 34 (2018) 2240-2245

68. T. Wen, S.Y. Liu, S. Chen, L.T. Liu, C. Yang, Influence of high frequency vibration on microstructure and mechanical properties of TIG welding joints of AZ31 magnesium alloy, Trans. Nonferrous Met. Soc. China (English Ed.) 25 (2015) 397-404

69. H. Li, J. Zhang, Y. Xiong, Enhancement of AZ80 joints using ultrasonic vibration-assisted welding process, Sci. Technol. Weld. Join. 23 (2018) 308-315

70. J. Zhou, Y. Wang, Effect of ultrasonic vibration field on tungsten inert gas welding of magnesium alloy and galvanized steel, Mater. Res. Express 6 (2018) 16519

71. T. Yuan, S. Kou, Z. Luo, Grain refining by ultrasonic stirring of the weld pool, Acta Mater. 106 (2016) 144-154

72. I. Hadley, 3-Fracture assessment methods for welded structures, in Woodhead Publishing Series in Welding and Other Joining Technologies, edited by S. Macdonald (Woodhead Publishing, 2011), pp. 60-90

73. J. Shen, Y. Li, X. Xie, M. Liu, Formation of stress cracking in an AZ61 magnesium alloy joint, Mater. Manuf. Process. 29 (2014) 188-193

74. G. Liang, S. Yuan, Study on the temperature measurement of AZ31B magnesium alloy in gas tungsten arc welding, Mater. Lett. 62 (2008) 2282-2284

75. V. Subravel, N. Alagappan, N. Babu, Influence of arc oscillation frequency on tensile properties and microstructural characteristics of magnetic arc oscillation welded AZ31B magnesium alloy joints, Mater. Today Proc. 22 (2020) 606-613

76. H.G. Dong, C.Q. Liao, L.Q. Yang, Microstructure and mechanical properties of AZ31B magnesium alloy gas metal arc weld, Trans. Nonferrous Met. Soc. China (English Ed). 22 (2012) 1336-1341
77. G. Song, P. Wang, Pulsed MIG welding of AZ31B magnesium alloy, Mater. Sci. Technol. 27 (2011) 518-524

78. L.L. Song Gang, W. Peng, Study on ac-PMIG welding of AZ31B magnesium alloy [J], Sci. Technol. Weld. Joining 15 (2010) 219-225

79. L.L. Song Gang, W. Peng, Study on ac-PMIG welding of AZ31B magnesium alloy [J], Sci. Technol. Weld. Joining 15 (2010) 219-225

80. Z. Zhang, X. Kong, Study on DC double pulse metal inert gas (MIG) welding of magnesium alloy, Mater. Manuf. Process. 27 (2012) 462-466

81. Y. Luo, H. Ye, C. Du, H. Xu, Influence of focusing thermal effect upon AZ91D magnesium alloy weld during vacuum electron beam welding, Vacuum 86 (2012) $1262-1267$

82. Y. Luo, Modeling and analysis of vaporizing during vacuum electron beam welding on magnesium alloy, Appl. Math. Model. 37 (2013) 6177-6182

83. E. Koleva, K. Vutova, G. Mladenov, The role of ingotcrucible thermal contact in mathematical modelling of the heat transfer during electron beam melting, Vacuum 62 (2001) 189-196

84. Y. Luo, H. Ye, C. Du, H. Xu, Influence of focusing thermal effect upon AZ91D magnesium alloy weld during vacuum electron beam welding, Vacuum 86 (2012) $1262-1267$

85. Y. Luo, Modeling and analysis of vaporizing during vacuum electron beam welding on magnesium alloy, Appl. Math. Model. 37 (2013) 6177-6182

86. H. Ye, H.L. Yang, Z.L. Yan, Study on electron beam welding of AZ61 magnesium alloy, Appl. Mech. Mater. 34-35 (2010) $1516-1520$

87. T. Asahina, H. Tokisue, Electron bean weldability of pure magnesium and AZ31 magnesium alloy, Mater. Trans. 42 (2001) 2345-2353

88. T. Asahina, H. Tokisue, Electron bean weldability of pure magnesium and AZ31 magnesium alloy, Mater. Trans. 42 (2001) 2345-2353

89. M. Wahba, M. Mizutani, Y. Kawahito, S. Katayama, Keyhole stability in disc laser welding of AZ31B and AZ61A magnesium alloys and weld metal properties, Sci. Technol. Weld. Join. 15 (2010) 559-566

90. M. Harooni, B. Carlson, B.R. Strohmeier, R. Kovacevic, Pore formation mechanism and its mitigation in laser welding of AZ31B magnesium alloy in lap joint configuration, Mater. Des. 58 (2014) 265-276

91. T. Yang, Y.L. Zhao, W.H. Liu, J.H. Zhu, J.J. Kai, C.T. Liu, Ductilizing brittle high-entropy alloys via tailoring valence electron concentrations of precipitates by controlled elemental partitioning, Mater. Res. Lett. 6 (2018) $600-606$

92. K. Hao, H. Wang, M. Gao, R. Wu, X. Zeng, Laser welding of AZ31B magnesium alloy with beam oscillation, J. Mater. Res. Technol. 8 (2019) 3044-3053

93. Y. Sakai, K. Nakata, T. Tsumura, M. Ueda, T. Ueyama, K. Akamatsu, Fiber laser welding of noncombustible magnesium alloy, Mater. Sci. Forum - MATER SCI FORUM 580-582 (2008) 479-482

94. J. Shen, L. Wen, Y. Li, D. Min, Effects of welding speed on the microstructures and mechanical properties of laser welded AZ61 magnesium alloy joints, Mater. Sci. Eng. A 578 (2013) 303-309 
95. S.H. Chowdhury, D.L. Chen, S.D. Bhole, E. Powidajko, D. C. Weckman, Y. Zhou, Fiber laser welded az31 magnesium alloy: the effect of welding speed on microstructure and mechanical properties, Metall. Mater. Trans. A Phys. Metall. Mater. Sci. 43 (2012) 2133-2147

96. J. Shen, L. Wen, Y. Li, D. Min, Effects of welding speed on the microstructures and mechanical properties of laser welded AZ61 magnesium alloy joints, Mater. Sci. Eng. A $\mathbf{5 7 8}$ (2013) 303-309

97. B.A. Mikucki, J.D. Shearouse, Interdependence of Hydrogen and Microporosity in Magnesium Alloy AZ91 (SAE International, 1993)

98. N. Seto, S. Katayama, A. Matsunawa, Porosity formation mechanism and suppression procedure in laser welding of aluminum alloy, Weld. Int. 15 (2001) 191-202

99. M. Harooni, F. Kong, B. Carlson, R. Kovacevic, Mitigation of pore generation in laser welding of magnesium alloy AZ31B in lap joint configuration, ASME Int. Mech. Eng. Congr. Expo. Proc. 3 (2012) 919-927

100. D.R. Mulinari, C.A.R.P. Baptista, J.V.C. Souza, H.J.C. Voorwald, Mechanical properties of coconut fibers reinforced polyester composites, Procedia Eng. 10 (2011) 2074 2079

101. M. Pastor, H. Zhao, R.P. Martukanitz, T. Debroy, Porosity, Underfill and magnesium loss during continuous wave $\mathrm{Nd}$ : YAG laser welding of thin plates of aluminum alloys 5182 and 5754, edited by A.B.T.-C.R.E. Sayigh (Elsevier, Oxford, 1999), pp. 207-216

102. C. Kammerhuber, R. Sommerfeld, High deposition MAG welding: used for welding bridges and structures, Weld. World / Le Soudage dans le Monde 38 (1996) 337-343

103. M. Harooni, B. Carlson, B.R. Strohmeier, R. Kovacevic, Pore formation mechanism and its mitigation in laser welding of AZ31B magnesium alloy in lap joint configuration, Mater. Des. 58 (2016) 265-276

104. J. Liu, J.H. Dong, K. Shinozaki, The welding of an ACM522 $\mathrm{Mg}$ alloy using a fiber laser, Mater. Sci. Forum 610-613 (2009) 911-914

105. L. Yu, K. Nakata, J. Liao, Weld porosity in fibre laser weld of thixomolded heat resistant $\mathrm{Mg}$ alloys, Sci. Technol. Weld. Join. 14 (2009) 554-558

106. K. Hao, H. Wang, M. Gao, R. Wu, X. Zeng, Laser welding of AZ31B magnesium alloy with beam oscillation, J. Mater. Res. Technol. 8 (2019) 3044-3053

107. M. Gao, H. Wang, K. Hao, H. Mu, X. Zeng, Evolutions in microstructure and mechanical properties of laser lap welded AZ31 magnesium alloy via beam oscillation, J. Manuf. Process. 45 (2019) 92-99

108. Z. Lei, J. Bi, P. Li, Q. Li, Y. Chen, D. Zhang, Melt flow and grain refining in ultrasonic vibration assisted laser welding process of AZ31B magnesium alloy, Opt. Laser Technol. 108 (2018) 409-417

109. Z.Q. Cui, H.W. Yang, W.X. Wang, Z.F. Yan, Z.Z. Ma, B.S. $\mathrm{Xu}, \mathrm{H} . \mathrm{Y}$. Xu, Research on fatigue crack growth behavior of AZ31B magnesium alloy electron beam welded joints based on temperature distribution around the crack tip, Eng. Fract. Mech. 133 (2015) 14-23

110. J. Liao, N. Yamamoto, K. Nakata, Gas tungsten arc welding of fine-grained AZ31B magnesium alloys made by powder metallurgy, Mater. Des. 56 (2014) 460-467

111. L. Liu, H. Sun, Study of flux assisted TIG welding of magnesium alloy with $\mathrm{SiC}$ particles in flux, Mater. Res. Innov. 12 (2008) 47-51
112. E.H. Amara, A. Bendib, Modelling of vapour flow in deep penetration laser welding, J. Phys. D. Appl. Phys. 35 (2002) 272-280

113. S. Zhang, G. Ma, X. Peng, Y. Xiang, Numerical simulation of the effects of bypass current on droplet transfer during AZ31B magnesium alloy DE-GMAW process based on FLUENT, Int. J. Adv. Manuf. Technol. 90 (2017) 857-863

114. C. Zhang, G. Ma, J. Nie, J. Ye, Numerical simulation of AZ31B magnesium alloy in DE-GMAW welding process, Int. J. Adv. Manuf. Technol. 78 (2015) 1259-1264

115. R. Baur, W.M. Steen, Laser Material Processing (third ed.) (Springer, Heidelberg, 2003)

116. E. Le Guen, R. Fabbro, M. Carin, F. Coste, P. Le Masson, Analysis of hybrid Nd:Yag laser-MAG arc welding processes, Opt. Laser Technol. 43 (2011) 1155-1166

117. M. Mazar Atabaki, M. Nikodinovski, P. Chenier, J. Ma, W. Liu, R. Kovacevic, Experimental and numerical investigations of hybrid laser arc welding of aluminum alloys in the thick T-joint configuration, Opt. Laser Technol. 59 (2014) 68-92

118. W.M. Steen, Arc augmented laser processing of materials, J. Appl. Phys. 51 (1980) 5636-5641

119. C. Bagger, F.O. Olsen, Review of laser hybrid welding, J. Laser Appl. 17 (2005) 2-14

120. U. Dilthey, F. Lueder, A. Wieschemann, Expanded capabilities in welding of aluminium alloys with laserMIG hybrid process, Aluminium 75 (1999) 64-75

121. T. Graf, H. Staufer, Laser-hybrid welding drives VW improvements, Weld. J. 82 (2003) 42-48

122. D. U, K. H, Prospects in laser-GMA hybrid welding of steel., Proc. 1st Int. WLT-Conference Lasers Manuf., Munich (2001) 453-65

123. Y.-P. Kim, N. Alam, H.-S. Bang, H.-S. Bang, Observation of hybrid (cw Nd:YAG laser + MIG) welding phenomenon in AA 5083 butt joints with different gap condition, Sci. Technol. Weld. Join. 11 (2006) 295-307

124. J.M. Vitek, S.A. David, M.W. Richey, J. Biffin, N. Blundell, C.J. Page, Weld pool shape prediction in plasma augmented laser welded steel, Sci. Technol. Weld. Join. 6 (2001) 305-314

125. S. Kirk Kanemaru, T. Sasaki, T. Sato, T. Era, M. Tanaka, Study for the mechanism of TIG-MIG hybrid welding process, Weld. World 59 (2015) 261-268

126. J. Shen, Y. Li, X. Xie, M. Liu, Formation of stress cracking in an AZ61 magnesium alloy joint, Mater. Manuf. Process. 29 (2014) 188-193

127. V. Subravel, G. Padmanaban, V. Balasubramanian, Effect of welding speed on microstructural characteristics and tensile properties of GTA welded AZ31B magnesium alloy, Trans. Nonferrous Met. Soc. China 24 (2014) 2776-2784

128. T. Wen, S.Y. Liu, S. Chen, L.T. Liu, C. Yang, Influence of high frequency vibration on microstructure and mechanical properties of TIG welding joints of AZ31 magnesium alloy, Trans. Nonferrous Met. Soc. China (English Ed). 25 (2015) 397-404

129. X. Xie, J. Shen, L. Cheng, Y. Li, Y. Pu, Effects of nanoparticles strengthening activating flux on the microstructures and mechanical properties of TIG welded AZ31 magnesium alloy joints, Mater. Des. 81 (2015) 31-38

130. F. Yang, J. Zhou, R. Ding, Ultrasonic vibration assisted tungsten inert gas welding of dissimilar magnesium alloys, J. Mater. Sci. Technol. 34 (2018) 2240-2245 
131. H. Al-Kazzaz, M. Medraj, X. Cao, M. Jahazi, Nd:YAG laser welding of aerospace grade ZE41A magnesium alloy: Modeling and experimental investigations, Mater. Chem. Phys. 109 (2008) 61-76

132. J. Dai, X. Wang, L. Yang, J. Huang, Y. Zhang, J. Chen, Study of plasma in laser welding of magnesium alloy, Int. J. Adv. Manuf. Technol. 73 (2014) 443-447

133. M. Harooni, B. Carlson, B.R. Strohmeier, R. Kovacevic, Pore formation mechanism and its mitigation in laser welding of AZ31B magnesium alloy in lap joint configuration, Mater. Des. 58 (2014) 265-276

134. Z. Lei, J. Bi, P. Li, Q. Li, Y. Chen, D. Zhang, Melt flow and grain refining in ultrasonic vibration assisted laser welding process of AZ31B magnesium alloy, Opt. Laser Technol. 108 (2018) 409-417

135. C.M. Lin, H.L. Tsai, C.L. Lee, D.S. Chou, J.C. Huang, Evolution of microstructures and properties of magnesium alloy weldments produced with $\mathrm{CO}_{2}$ laser process, Mater. Sci. Eng. A 548 (2012) 12-18

136. D.X. Ren, L.M. Liu, Effect of adhesive induced gas on penetration and plasma behaviour in laser weld bonding of magnesium alloy, Mater. Res. Innov. 14 (2010) 405-409

137. M. Sahul, M. Sahul, J. Lokaj, Effect of surface layer on the properties of AZ31 magnesium alloy welded joints, Mater. Today Proc. 3 (2016) 1150-1155

138. F. Scherm, J. Bezold, U. Glatzel, Laser welding of $\mathrm{Mg}$ alloy MgAl3zn1 (AZ31) to Al alloy AlMg3 (AA5754) using ZnAl filler material, Sci. Technol. Weld. Join. 17 (2012) 364-367

139. X. Zhang, Z. Cao, Pulsed Nd:YAG laser spot welding of an AZ31 magnesium alloy, Int. J. Adv. Manuf. Technol. 104 (2019) 3053-3063

140. X. Zhang, Z. Cao, P. Zhao, Investigation on solidification cracks in pulsed laser spot welding of an AZ31 magnesium alloy, Opt. Laser Technol. 126 (2020) 106132

141. M. Rethmeier, B. Kleinpeter, H. Wohlfahrt, MIG welding of magnesium alloys metallographic aspects, Weld. World 48 (2004) 28-33

142. G. Song, P. Wang, L.M. Liu, Study on ac-PMIG welding of AZ31B magnesium alloy, Sci. Technol. Weld. Join. 15 (2010) 219-225

143. Z.D. Zhang, L.M. Liu, G. Song, Welding characteristics of AZ31B magnesium alloy using DC-PMIG welding, Trans. Nonferrous Met. Soc. China (English Ed.) 23 (2013) 315322

144. H. Huang, J. Chen, Y.C. Lim, X. Hu, J. Cheng, Z. Feng, X. Sun, Heat generation and deformation in ultrasonic welding of magnesium alloy AZ31, J. Mater. Process. Technol. 272 (2019) 125-136

145. C. Li, M. Chen, S. Yuan, L. Liu, Effect of welding speed in high speed laser-TIG welding of magnesium alloy, Mater. Manuf. Process. 27 (2012) 1424-1428

146. C. Li, L. Liu, Investigation on weldability of magnesium alloy thin sheet T-joints: Arc welding, laser welding, and laser-arc hybrid welding, Int. J. Adv. Manuf. Technol. 65 (2013) 27-34

147. X. Shen, G. Ma, P. Chen, Effect of welding process parameters on hybrid GMAW-GTAW welding process of AZ31B magnesium alloy, Int. J. Adv. Manuf. Technol. 94 (2018) 2811-2819

148. R.Z. Xu, G. Song, Z. Wang, Corrosion characteristics of AZ91 magnesium alloy weldments, Mater. Res. Innov. 13 (2009) 441-447
149. R. Manti, D.K. Dwivedi, Microstructure of Al-Mg-Si weld joints produced by pulse TIG welding, Mater. Manuf. Process. 22 (2007) 57-61

150. U. of A. (New Z. Zhu Tianping [Department of Chemical and Materials Engineering E-mail: tzhu004@ec.auckland. ac.nz, Z.W. [Department of M. and P.E. Chen Auckland University of Technology (New Zealand)], and G. [Department of C. and M.E. Wei University of Auckland (New Zealand)], Microstructure formation in partially melted zone during gas tungsten arc welding of AZ91 Mg cast alloy, 2008

151. Y.J. Quan, Z.H. Chen, X.S. Gong, Z. Yu, Effects of heat input on microstructure and tensile properties of laser welded magnesium alloy AZ31, Mater. Charact. 59 (2008) 1491-1497

152. L. Liu, X. Hao, Low-power laser/TIG hybrid welding process of magnesium alloy with filler wire, Mater. Manuf. Process. 25 (2010) 1213-1218

153. W. Wang, P. Han, K. Qiao, T. Li, K. Wang, J. Cai, L. Wang, Effect of the rotation rate on the low-cycle fatigue behavior of friction-stir welded AZ31 magnesium alloy, Eng. Fract. Mech. 228 (2020) 106925

154. W. Wang, P. Han, K. Qiao, T. Li, K. Wang, J. Cai, L. Wang, Effect of the rotation rate on the low-cycle fatigue behavior of friction-stir welded AZ31 magnesium alloy, Eng. Fract. Mech. 228 (2020) 106925

155. S. Celik, R. Cakir, Effect of friction stir welding parameters on the mechanical and microstructure properties of the Al$\mathrm{Cu}$ butt joint, Metals (Basel). 6 (2016) doi: 10.3390/ met6060133

156. L. Ceschini, I. Boromei, G. Minak, A. Morri, F. Tarterini, Effect of friction stir welding on microstructure, tensile and fatigue properties of the AA7005/10 vol.\%Al2O3p composite, Compos. Sci. Technol. 67 (2007) 605-615

157. B.S. Naik, D.L. Chen, X. Cao, P. Wanjara, Texture development in a friction stir lap-welded AZ31B magnesium alloy, Metall. Mater. Trans. A Phys. Metall. Mater. Sci. 45 (2014) 4333-4349

158. P. Gulati, D.K. Shukla, A. Gupta, M. Singh, R. Kumar, J.P. Singh, Microstructural analysis of friction stir welded $\mathrm{Mg}$ AZ31 alloy, Mater. Today Proc. (2020) 2-7

159. B. Rajabharathi, A.K. Lakshminarayanan, T. Ram Prabhu, Impact of friction diffusion welding parameters on the properties of rare earth containing magnesium alloy tube-tube plate welds, J. Alloys Compd. 712 (2017) 355-364

160. R. Senthilraja, A.N. Sait, Optimization of the parameters of friction stir welding for AZ91D magnesium alloy using the Taguchi design, Mater. Sci. 51 (2015) 180-187

161. P. Gulati, D.K. Shukla, A. Gupta, M. Singh, R. Kumar, J.P. Singh, Microstructural analysis of friction stir welded $\mathrm{Mg}$ AZ31 alloy, Mater. Today Proc. (2020) 2-7

162. M. Mirzaei, P. Asadi, A. Fazli, Effect of tool pin profile on material flow in double shoulder friction stir welding of AZ91 magnesium alloy, Int. J. Mech. Sci. 183 (2020) 105775

163. G. Li, L. Zhou, S. Luo, F. Dong, N. Guo, Microstructure and mechanical properties of bobbin tool friction stir welded ZK60 magnesium alloy, Mater. Sci. Eng. A 776 (2020) 138953

164. S.J. Sun, J.S. Kim, W.G. Lee, J.Y. Lim, Y. Go, Y.M. Kim, Influence of friction stir welding on mechanical properties of butt joints of AZ61 magnesium alloy, Adv. Mater. Sci. Eng. 2017 (2017) doi: 10.1155/2017/7381403 
165. F. Baradarani, A. Motafapour, M. Shalvandi, Effect of ultrasonic assisted friction stir welding on microstructure and mechanical properties of AZ91-C magnesium alloy, Trans. Nonferrous Met. Soc. China (English Ed.) 29 (2019) $2514-2522$

166. S.H. Chowdhury, D.L. Chen, S.D. Bhole, X. Cao, P. Wanjara, Friction stir welded AZ31 magnesium alloy: microstructure, texture, and tensile properties, Metall. Mater. Trans. A Phys. Metall. Mater. Sci. 44 (2013) 323-336

167. G. Li, L. Zhou, S. Luo, F. Dong, N. Guo, Microstructure and mechanical properties of bobbin tool friction stir welded ZK60 magnesium alloy, Mater. Sci. Eng. A 776 (2020) 138953

168. G. Li, L. Zhou, J. Zhang, S. Luo, N. Guo, Macrostructure, microstructure and mechanical properties of bobbin tool friction stir welded ZK60 Mg alloy joints, J. Mater. Res. Technol. 9 (2020) 9348-9361

169. G. Li, L. Zhou, J. Zhang, S. Luo, N. Guo, Macrostructure, microstructure and mechanical properties of bobbin tool friction stir welded ZK60 Mg alloy joints, J. Mater. Res. Technol. 9 (2020) 9348-9361

170. P. Asadi, M.K.B. Givi, M. Akbari, Microstructural simulation of friction stir welding using a cellular automaton method: A microstructure prediction of AZ91 magnesium alloy, Int. J. Mech. Mater. Eng. 10 (2015) doi: 10.1186/ s40712-015-0048-5

171. H. Bin Chen, K. Yan, T. Lin, S. Ben Chen, C.Y. Jiang, Y. Zhao, The investigation of typical welding defects for 5456 aluminum alloy friction stir welds, Mater. Sci. Eng. A 433 (2006) 64-69

172. F. Baradarani, A. Mostafapour, M. Shalvandi, Effect of ultrasonic assisted friction stir welding on microstructure and mechanical properties of AZ91-C magnesium alloy, Trans. Nonferrous Met. Soc. China (English Ed.) 29 (2019) 2514-2522

173. G.K. Padhy, C.S. Wu, S. Gao, Auxiliary energy assisted friction stir welding - status review, Sci. Technol. Weld. Join. 20 (2015) 631-649

174. Z. Liu, X. Meng, S. Ji, Z. Li, L. Wang, Improving tensile properties of $\mathrm{Al} / \mathrm{Mg}$ joint by smashing intermetallic compounds via ultrasonic-assisted stationary shoulder friction stir welding, J. Manuf. Process. 31 (2018) 552-559

175. Z. Liu, X. Meng, S. Ji, Z. Li, L. Wang, Improving tensile properties of $\mathrm{Al} / \mathrm{Mg}$ joint by smashing intermetallic compounds via ultrasonic-assisted stationary shoulder friction stir welding, J. Manuf. Process. 31 (2018) $552-559$

176. A.H. Feng, D.L. Chen, Z.Y. Ma, W.Y. Ma, R.J. Song, Microstructure and strain hardening of a friction stir welded high-strength Al-Zn-Mg alloy, Acta Metall. Sin. (English Lett.) 27 (2014) 723-729

177. S.H. Chowdhury, D.L. Chen, S.D. Bhole, X. Cao, P. Wanjara, Friction stir welded AZ31 magnesium alloy: microstructure, texture, and tensile properties, Metall. Mater. Trans. A 44 (2013) 323-336

178. B.S. Naik, D.L. Chen, X. Cao, P. Wanjara, Microstructure and fatigue properties of a friction stir lap welded magnesium alloy, Metall. Mater. Trans. A Phys. Metall. Mater. Sci. 44 (2013) 3732-3746
179. F. Pan, A. Xu, D. Deng, J. Ye, X. Jiang, A. Tang, Y. Ran, Effects of friction stir welding on microstructure and mechanical properties of magnesium alloy Mg-5Al-3Sn, Mater. Des. 110 (2016) 266-274

180. S. Borle, H. Izadi, A.P. Gerlich, Influence of welding parameters on stir zone microstructures during friction stir welding of magnesium alloys, Can. Metall. Q. 51 (2012) 262-268

181. B. Rajabharathi, A.K. Lakshminarayanan, T. Ram Prabhu, Impact of friction diffusion welding parameters on the properties of rare earth containing magnesium alloy tubetube plate welds, J. Alloys Compd. 712 (2017) 355-364

182. S. Satonaka, C. Iwamoto, G.I. Murakami, Y. Matsumoto, Resistance spot welding of magnesium alloy sheets with cover plates, Weld. World 56 (2012) 44-50

183. M. Mirzaei, P. Asadi, A. Fazli, Effect of tool pin profile on material flow in double shoulder friction stir welding of AZ91 magnesium alloy, Int. J. Mech. Sci. 183 (2020) 105775

184. P. Asadi, M.K.B. Givi, M. Akbari, Microstructural simulation of friction stir welding using a cellular automaton method: a microstructure prediction of AZ91 magnesium alloy, Int. J. Mech. Mater. Eng. 10 (2015), doi: 10.1186/ s40712-015-0048-5

185. L.C. Campanelli, U.F.H. Suhuddin, A.Í.S. Antonialli, J.F. Dos Santos, N.G. De Alcântara, C. Bolfarini, Metallurgy and mechanical performance of AZ31 magnesium alloy friction spot welds, J. Mater. Process. Technol. 213 (2013) 515-521

186. J. Chen, R. Ueji, H. Fujii, Double-sided friction-stir welding of magnesium alloy with concave-convex tools for texture control, Mater. Des. 76 (2015) 181-189

187. S.H. Chowdhury, D.L. Chen, S.D. Bhole, X. Cao, P. Wanjara, Friction stir welded AZ31 magnesium alloy: microstructure, texture, and tensile properties, Metall. Mater. Trans. A 44 (2013) 323-336

188. L. Commin, M. Dumont, R. Rotinat, F. Pierron, J.E. Masse, L. Barrallier, Influence of the microstructural changes and induced residual stresses on tensile properties of wrought magnesium alloy friction stir welds, Mater. Sci. Eng. A 551 (2012) 288-292

189. A. Dhanapal, S. Rajendra Boopathy, V. Balasubramanian, Corrosion behaviour of friction stir welded AZ61A magnesium alloy welds immersed in $\mathrm{NaCl}$ solutions, Trans. Nonferrous Met. Soc. China (English Ed.) 22 (2012) 793-802

190. A. Forcellese, M. Martarelli, M. Simoncini, Effect of process parameters on vertical forces and temperatures developed during friction stir welding of magnesium alloys, Int. J. Adv. Manuf. Technol. 85 (2016) 595-604

191. P. Gulati, D.K. Shukla, A. Gupta, Defect formation analysis of friction stir welded magnesium AZ31B alloy, Mater. Today Proc. 4 (2017) 1005-1012

192. A.F. Hasan, CFD modelling of friction stir welding (FSW) process of AZ31 magnesium alloy using volume of fluid method, J. Mater. Res. Technol. 8 (2019) 1819-1827

193. J. Hiscocks, B.J. Diak, A.P. Gerlich, M.R. Daymond, Formation mechanisms of periodic longitudinal microstructure and texture patterns in friction stir welded magnesium AZ80, Mater. Charact. 122 (2016) 22-29

194. W. Li, P.L. Niu, S.R. Yan, V. Patel, Q. Wen, Improving microstructural and tensile properties of AZ31B magnesium alloy joints by stationary shoulder friction stir welding, J. Manuf. Process. 37 (2019) 159-167 
195. S. Mironov, Y.S. Sato, H. Kokawa, Influence of welding temperature on material flow during friction stir welding of AZ31 magnesium alloy, Metall. Mater. Trans. A Phys. Metall. Mater. Sci. 50 (2019) 2798-2806

196. F. Pan, A. Xu, D. Deng, J. Ye, X. Jiang, A. Tang, Y. Ran, Effects of friction stir welding on microstructure and mechanical properties of magnesium alloy Mg-5Al-3Sn, Mater. Des. 110 (2016) 266-274

197. K. Singh, G. Singh, H. Singh, Microstructure and mechanical behaviour of friction-stir-welded magnesium alloys: AsWelded and post weld heat treated, Mater. Today Commun. 20 (2019) 100600

198. X. Xie, J. Shen, F. Gong, D. Wu, T. Zhang, X. Luo, Y. Li, Effects of dwell time on the microstructures and mechanical properties of water bath friction stir spot-welded AZ31 magnesium alloy joints, Int. J. Adv. Manuf. Technol. 82 (2016) $75-83$

199. S.D. Ji, Z.W. Li, L. Ma, Y.M. Yue, S.S. Gao, Investigation of ultrasonic assisted friction stir spot welding of magnesium alloy to aluminum alloy, Strength Mater. 48 (2016) 2-7

200. A. Macwan, D.L. Chen, Ultrasonic spot welding of a rareearth containing ZEK100 magnesium alloy: effect of welding energy, Metall. Mater. Trans. A Phys. Metall. Mater. Sci. 47 (2016) 1686-1697

201. R. Qiu, N. Wang, H. Shi, K. Zhang, S. Satonaka, Nonparametric effects on pore formation during resistance spot welding of magnesium alloy, Sci. Technol. Weld. Join. 19 (2014) 231-234

202. X. Wei Yang, W. Yuan Feng, W. Ya Li, X. Rong Dong, Y. $\mathrm{Xin} \mathrm{Xu}, \mathrm{Q}$. Chu, S. Tian Yao, Microstructure and properties of probeless friction stir spot welding of AZ31 magnesium alloy joints, Trans. Nonferrous Met. Soc. China (English Ed.) 29 (2019) 2300-2309

203. W. Zhou, T.Z. Long, C.K. Mark, Hot cracking in tungsten inert gas welding of magnesium alloy AZ91D, Mater. Sci. Technol. 23 (2007) 1294-1299

204. X. Xie, J. Shen, L. Cheng, Y. Li, Y. Pu, Effects of nanoparticles strengthening activating flux on the microstructures and mechanical properties of TIG welded AZ31 magnesium alloy joints, Mater. Des. 81 (2015) 31-38

205. J. Liao, N. Yamamoto, K. Nakata, Gas tungsten arc welding of fine-grained AZ31B magnesium alloys made by powder metallurgy, Mater. Des. 56 (2014) 460-467

206. C.-M. Lin, H.-L. Tsai, C.-L. Lee, D.-S. Chou, J.-C. Huang, Evolution of microstructures and properties of magnesium alloy weldments produced with $\mathrm{CO}_{2}$ laser process, Mater. Sci. Eng. A 548 (2012) 12-18

207. M. Sahul, M. Sahul, J. Lokaj, Effect of surface layer on the properties of AZ31 magnesium alloy welded joints, Mater. Today Proc. 3 (2016) 1150-1155

208. J. Chen, R. Ueji, H. Fujii, Double-sided friction-stir welding of magnesium alloy with concave-convex tools for texture control, Mater. Des. 76 (2015) 181-189

209. W. Li, P.L. Niu, S.R. Yan, V. Patel, Q. Wen, Improving microstructural and tensile properties of AZ31B magnesium alloy joints by stationary shoulder friction stir welding, J. Manuf. Process. 37 (2019) 159-167

210. S. Niknejad, L. Liu, M.Y. Lee, S. Esmaeili, N.Y. Zhou, Resistance spot welding of AZ series magnesium alloys: Effects of aluminum content on microstructure and mechanical properties, Mater. Sci. Eng. A 618 (2014) $323-334$

Cite this article as: Desmond Edem Primus Klenam, Gabriel Seun Ogunwande, Taiwo Omotosho, Blessing Ozah, Nthabiseng Beauty Maledi, Silas Ithete Hango, Adefunke Abosede Fabuyide, Lesego Mohlala, Josias Willem van der Merwe, Michael Oluwatosin Bodunrin, Welding of magnesium and its alloys: an overview of methods and process parameters and their effects on mechanical behaviour and structural integrity of the welds, Manufacturing Rev. 8, 29 (2021) 